\title{
¿Qué es la Filología de autor? ${ }^{1}$
}

\author{
Paola Italia \\ Universidad de Roma "La Sapienza"
}

\author{
Giulia Raboni \\ Universidad de Parma
}

Título: ¿Qué es la Filología de autor?

Resumen: Este artículo pretende definir la filología de autor y, para ello, atenderá a su génesis, donde cobran especial importancia las figuras de Contini e Isella, a sus premisas básicas, que la diferencian de la crítica genética francesa y al radical cambio al que está sometida hoy nuestra disciplina. La filología de autor, que implica además una interpretación personal por parte del crítico, refleja dicha interpretación no solo en la lección escogida del texto, sino en la propia construcción del aparato crítico, que podrá ser genético o evolutivo. Todas estas cuestiones básicas se explican a partir de los Idilli de Leopardi o Fermo e Lucia de Manzoni, entre otros ejemplos.
Title: What is the Philology Author?

Abstract: The aim of the article is to define author's philology, and in order to do so, it will look at its beginnings, where we find the relevance of the figures of Contini an Isella, at its basic premises, which make it differ from French genetic criticism, and at the radical transformation to which our discipline is exposed today. Author's philology, which also entails a personal interpretation on the critic's part, projects this interpretation not only in the lesson chosen from the text, but also in the construction itself of the critical apparatus, which may be genetic or evolutive. All these basic issues are dealt with taking the Idilli, by Leopardi, or Fermo e Lucia, by Manzoni, as basis, among others.

Key words: Philology author, Genetic critic, Critical apparatus, Variants.

Date of Receipt: 14/2/2014.

Date of Approval: 22/4/2014.

Fecha de aceptación: 22/4/2014.

Palabras clave: Filología de autor, Crítica genética, Aparato crítico, Variantes.

Fecha de recepción: 14/2/2014.

1 Traducción de Paolo Tanganelli (Universidad de Ferrara, Italia).

2 Del volumen de Paola Italia y Giulia Raboni, Che cosè la filologia d'autore, Roma, Carocci, 2010, se traducen los últimos tres apartados del primer capítulo (pp. 26-37) y el segundo capítulo (pp. 38-71). De la parte traducida, Giulia Raboni ha escrito el apartado $\$ 1.2$. La filología de autor de Dante Isella, mientras que del resto es responsable Paola Italia (N. d. T.). 


\section{Historia}

\section{I. La Filología de AUTOR y la CRITIQUE GÉNÉTIQUE}

La filología de autor ha desarrollado un nuevo modo de considerar los textos que deriva de un diferente planteamiento, aun desde un punto de vista filosófico, de la literatura. En efecto, para la filología de autor y la crítica de las variantes la poeticidad del texto no es un "dato", un "valor" establecido, sino, como ya se ha dicho, una "aproximación al valor" que comprende -y es el resultado de- todos los textos que lo han precedido, todos sus antetextos.

Empleamos la palabra "antetexto" - de derivación francesa: avantexte-, que también en Italia ha tenido cierta aplicación; es necesaria, sin embargo, una aclaración, puesto que esta a menudo se emplea con acepciones distintas. El término, introducido por Jean Bellemin-Noël, se ha utilizado en Francia para indicar "el conjunto de los materiales preparatorios recogidos, descifrados, clasificados: de las simples listas de palabras a notas y dibujos, de los primeros mínimos borradores a auténticas redacciones"3; pero con ampliaciones semánticas se ha extendido también a ámbitos no estrictamente filológicos (como sucede cuando en el antetexto se incluye, por ejemplo, también el itinerario mental del autor).

En la filología de autor aplicada en Italia, en cambio, con "antetexto" se indica solo el conjunto de los datos materiales relativos a todo lo que ha precedido el texto. En esta acepción es posible distinguir entre:

1) materiales que no tienen relación directa con el texto (como listas de personajes, proyectos literarios, listas léxicas etc.);

2) materiales inmediatamente relacionados con el texto (como las primeras redacciones y las sucesivas refundiciones que preceden al texto verdadero).

3 Alfredo Stussi, Introduzione agli studi di Filologia italiana, Bolonia, Il Mulino, 1994 (en particular las pp. 155-261, dedicadas a la filología de autor). Cf. también Alfredo Stussi, Introduzione agli studi di Filologia italiana, Bolonia, il Mulino, 2006. 
De esta diferente consideración proceden dos tipos diversos de edición crítica: la francesa (más conocida como édition génétique) y la tudesco-italiana (generalmente definida como "edición crítica" o edición "crítico-genética").

La edición genética francesa se caracteriza por el hecho de presentar la edición integral de todo el antetexto, desde los primeros apuntes hasta las correcciones de las pruebas de imprenta, sin distinguir entre el primero y el segundo tipo de antetexto, y sin subordinar al texto la parte de antetexto directamente ligada a él; véase, por ejemplo, la edición en 29 volúmenes de los Cahiers de Paul Valéry publicada de 1957 a 1961, o bien la edición de Un coeur simple en el Corpus flaubertianum que ha publicado G. Bonaccorso para Les Belles Lettres (París, 1983).

La édition génétique es, por tanto, una representación de la historia del texto a través de fotogramas aislados, cada uno de los cuales fija un estatus provisional de aquel itinerario sin distinción ninguna entre texto, materiales preparatorios y aparato.

La edición tudesco-italiana, en cambio, tiende a dar mayor importancia al proceso de corrección, del cual la lección que aparece en el texto constituye el producto final, y en consecuencia considera tan solo la parte de antetexto que guarda una relación directa con tal "producto".

Por lo tanto, la edición crítica (o crítico-genética) focaliza la atención sobre el recorrido genético o evolutivo del texto; es decir, sobre el movimiento variantístico que conduce de las lecciones registradas en el aparato a aquellas puestas en el texto (o viceversa).

La característica peculiar de una edición crítica de filología de autor de corte italiano, en consecuencia, consiste en colocar inmediatamente al lector delante de un doble organismo textual, que ocupa también dos zonas tipográficas diferentes: el texto y el aparato; donde el segundo siempre se subordina al primero: al pie de la página, al final del texto o en un volumen separado.

Los materiales no directamente relacionados con el texto no se incluyen en la edición, sino que se suelen publicar en una posición subordinada (en un apéndice o, en el caso de materiales particularmente numerosos, en un volumen separado).

En particular, para editar un texto in fieri el trabajo del filólogo no debería tanto intentar seguir al ralentí el acto de la escritura, lo cual sería una ingenua y tal vez inútil presunción (ni siquiera el autor sabe, ya que 
no puede recordarlas de forma detallada, todas las fases que se han sucedido en su mente, desde la primigenia idea del texto hasta la redacción final), como traducir la oscuridad del manuscrito en signos claros, representando, a ser posible, la cronología de la composición que se ha logrado reconstruir, y que -cuestión más importante- constituye una hipótesis del filólogo sobre lo que acontece "antes del texto" y que lleva al texto a ser lo que es.

En otras palabras, a través del análisis de los manuscritos no se deberían vaticinar los itinerarios mentales del autor, sino elaborar "criterios de formalización del aparato y [...] sistemas capaces de reproducir de la mejor forma (en todas sus fases internas, oportunamente distintas y relacionadas entre ellas) el proceso elaborativo del escritor tanto en los manuscritos como en los impresos" $"$.

Si entonces el filólogo construye, a partir del estudio de las variantes, su hipótesis, el aparato no es otra cosa que la concreta aplicación de dicha hipótesis, la ley que describe de la manera más racional y económica la serie de los fenómenos empíricos observados, y que, como toda ley científica, se debe considerar válida hasta que no emerja un dato que no resulte incluido en ella y que, por tanto, invalide el aparato u obligue por lo menos a algunos pequeños arreglos.

De ello deriva el carácter experimental de cada intento de formalización y la imposibilidad de elaborar un único aparato para series no homogéneas de fenómenos. Vale decir que, considerado que cada autor posee un sistema de corrección personal, así como un estilo propio, una poética propia, una estrategia propia de composición, en cada caso concreto se tratará de elaborar un método de representación adecuado a ese sistema de corrección.

De hecho no existe, según se ha dicho ya, un aparato ideal, como no existe la edición crítica ideal, y lo que puede estar bien con un autor no funciona con otro. Verga no corrige como Gadda, que, paradójicamente, enmienda de forma más parecida a Bembo, aun cuando ambos autores no se puedan asemejar bajo ningún punto de vista. Cuando los estudios de filología de autor sean más numerosos y la disciplina más codificada, acaso se podrá escribir una historia de la literatura italiana sobre la base de

4 Dante Isella, Le carte mescolate, Padova, Liviana, 1987, p. 16. 
los variados sistemas de corrección de los autores y de sus relaciones con los manuscritos. Sin duda saldrían de ahí unas aproximaciones nuevas e interesantes, porque, a través del cotejo con el texto relativo, se podrían sacar indicaciones útiles sobre la poética y hasta la ideología de un escritor.

\section{I.2. La Filología de aUtor de Dante Isella}

Un hito en la delineación de la disciplina de la edición de textos de autor, tanto en la forma de la publicación de textos in fieri como de obras conservadas en varias redacciones, es la publicación en 1987 del volumen de Isella Le carte mescolate. Esperienze di filologia d'autore, del cual, como ya se ha dicho, procede la feliz denominación, que hoy forma parte del patrimonio común, de "filología de autor" (en oposición a la anterior denominación de "fenomenología del original", según la definición de D’Arco Silvio Avalle).

Discípulo de Contini en Friburgo, Isella opera a partir de los años cincuenta del Novecientos en el campo de la edición de textos sometidos a trabajo variantístico, produciendo una serie de ediciones, cada vez más refinadas desde el punto de vista de la elaboración de aparatos críticos, de textos basculantes entre el XVI y la edad contemporánea, cada uno de ellos caracterizado por problemáticas distintas, que le permiten inventar instrumentos editoriales ad hoc.

El ensayo que abre el volumen, "Le varianti d'autore (critica e filologia)", lección inaugural leída en ocasión de la toma de posesión de la cátedra de Literatura italiana en el Politécnico de Zúrich, nos brinda un primer epítome de la historia de la disciplina, empezando por el nacimiento teórico a partir de la polémica Croce-De Robertis-Contini ${ }^{5}$ para luego delinear sobre todo la posición continiana, ligada por un lado a la estética del filósofo napolitano (respecto a la cual, en el ensayo ariostesco, Contini había subrayado la perfecta complementariedad, confiando al examen de las variantes una especie de función de control de las descripciones "caracterizadoras" de la crítica de Croce), y por otro a la crítica

5 Cf. Paola Italia y Gulia Raboni, "La filologia d'autore e la critica delle varianti”, en Che cos'è la filologia d'autore, pp. 22-26. 
estilística de Leo Spitzer, enmendada y verificada a través del cotejo no ya entre la lengua individual del autor y una norma lingüística abstracta, sino entre las sucesivas elecciones del autor.

De este agudo enfoque, que Contini sistematizó e incrementó aún más con las aportaciones del estructuralismo, que le permitieron superar la consideración "atomística” de las variantes individuales (típica, por ejemplo, del contemporáneo planteamiento crítico de De Robertis) en favor de una consideración sistémica del movimiento correccional (particularmente fecunda en el análisis de la poesía leopardiana), brotan las empresas filológicas que distinguen las propuestas de la crítica italiana a partir de los ańos cuarenta, cuya novedad Isella pretende ejemplificar en los capítulos sucesivos del volumen, pasando, con un cambio de ángulo visual, de la teoría a la práctica. Sin embargo, justo este cambio produce, a su vez, de manera implícita, una corrección decisiva en la relación entre la filología y la crítica, porque privilegia el primer elemento que, desde ese momento, resultará no solo cada vez más complementario y parejo respecto al segundo (progreso ya notable si lo comparamos con el papel ancilar de la filología en la perspectiva de Croce), sino también capaz, en la elaboración de una propia metodología, de generar por sí mismo algunas perspectivas críticas que no se hubieran podido hallar de otra manera.

En otras palabras, mientras que en Contini (el cual - no es ninguna casualidad- no ha producido directamente ediciones de autor excepto la de la Opera in versi de Montale, realizada con Rosanna Bettarini, contando con la colaboración del mismo poeta) el acto crítico acontece a posteriori sobre el material que ofrecen las ediciones genéticas (la edición de Debenedetti para el Furioso, la de Moroncini y luego la de Peruzzi para los Cantos de Leopardi), en los ejemplos ilustrados por Isella, que se enfrentan a casos muy complejos de tradición, la construcción del aparato comienza con la razonada ordenación de los papeles y con la interpretación del iter correccional: la misma ecdótica -la ciencia que examina los problemas ligados a las ediciones de los textos- es entonces, a su vez y de por sí, un acto interpretativo; lo cual impone tanto una mayor responsabilidad del editor-filólogo, obligado a plasmar las elecciones metodológicas sobre la base de su propia hipótesis reconstructiva, como la adopción de instrumentos de representación a la vez más analíticos y más maleables, que deben adaptarse a las diferentes situaciones textuales. 
A la ilustración de algunos casos particularmente significativos, y a trazar el esquema de "un hipotético breviario" de filología de autor, se dedican, en efecto, los otros tres capítulos del volumen de Isella. Más metodológico y compendioso es el primero (Le testimonianze autografe pluri$m e$ ), que aclara la situación de tres casos intrincados de filología de autor, como son las rimas amorosas de Tasso, las rimas dispersas de Parini y las primeras redacciones de los Promessi sposi (el Fermo e Lucia y el llamado "Segundo Borrador"), mientras que los dos siguientes son monográficos y analíticos: uno se centra de nuevo, aunque con mayor profundidad, sobre las rimas tassianas, y otro sobre el Giorno de Parini (se trata de la introducción a la edición crítica de este poema, publicada en 1969). En todos estos casos Isella focaliza su atención sobre las peculiaridades de la situación textual de las obras examinadas, llegando a formular propuestas nuevas y estrictamente adherentes al cuadro interpretativo delineado.

En particular, es fundamental la insistencia, en los casos tanto del cancionero tassiano como de las diversas redacciones del poema de Parini, sobre la necesidad de separar las diferentes fases redaccionales (que se corresponden con distintas sistematizaciones del autor) y de fabricar aparatos directamente funcionales para representar un determinado segmento variantístico. Precisamente desde este punto de vista, en el estudio del Giorno de Parini, Isella introduce la distinción entre los aparatos genético y evolutivo con relación al mismo manuscrito: uno para registrar la elaboración genética que precede al texto base (a su vez provisional, aunque haya llegado a un estado sólido de definición), otro para documentar aquellas variantes que buscan su superación, si bien sin cristalizarse en una revisión integral y coherente, y que por lo tanto testimonian una fase de búsqueda radicalmente diferente con respecto a aquella representada por el sucesivo estado redaccional.

Esta adherencia al texto, con una sensibilidad en el registro - para usar las palabras de Isella- igual que la del lápiz del sismógrafo, obliga a buscar en los aparatos una formalización adecuada y cortada a medida -por así decir- de la particular metodología correccional de los autores: así, si la intervención típica de Gadda es incrementar a posteriori el período, mediante añadidos interlineales y marginales que se pueden representar entonces de manera más fotográfica, la de Manzoni se caracteriza en cambio por el desarrollo a partir de una frase "base" de implicaciones lógicas que 
se articulan sintácticamente en nuevos segmentos, y que, al comportar por lo tanto la sustitución de la primera escritura currenti calamo con las formulaciones sucesivas, requieren una representación más compacta que permita la visualización y la comparación de la estructura completa sujeta a variación, conforme a una jerarquización de las fases que debe ser la más completa posible. Eso es lo que de hecho sucede en los diferentes aparatos predispuestos tanto para los textos de Gadda, como para la edición crítica del Fermo e Lucia, la cual se orienta de manera neta hacia una representación interpretativa que privilegia la posibilidad de confrontar segmentos autónomos de texto respecto a la indicación puntual y topográfica.

Sin duda, entre ambos proyectos median también años de nuevas experiencias, que han acometido directamente Isella o su escuela, refinando cada vez más los criterios editoriales: así, si a partir justo de la edición del Racconto italiano di ignoto del Novecento de Gadda, publicado en 1983, Isella ha podido precisar con claridad la distinción de un triple filtro de niveles textuales formado por (1) aparato, (2) apostillas, (3) variantes alternativas, luego utilizado en la edición integral de las obras gaddianas impresas en la colección la "Spiga" de Garzanti a partir de 1988 (donde no todos los textos están dotados de aparato, pero en todos ellos una "Nota al texto" informa de modo exhaustivo sobre la situación redaccional), quizá sea en la edición de los Malavoglia de Verga preparada por un discípulo de Isella, Ferruccio Cecco (1995), donde se detallan algunas técnicas fundamentales para la construcción de los aparatos lineares de textos en prosa.

Por primera vez, en la edición de Cecco se experimenta con un aparato diacrónico (cf. apartado 2.3.3), en el cual los segmentos textuales se disponen en orden cronológico, separados y jerarquizados a través de una serie de números volados hasta la última fase, que se lee en el texto, cuyas variantes menores se precisan entre paréntesis. Es esta una forma de representación sintética y sumamente exegética, puesto que en un largo período en prosa no siempre es fácil decidir qué elementos se han introducidos simultáneamente y cuáles sucesivamente, y el filólogo debe entonces tomar en cuenta todos los indicios gráficos, topográficos, como también lingüísticos y semánticos, a su disposición para establecer la cronología. Además, en esta edición Cecco toma en consideración y soluciona los problemas relativos a la representación de los antetextos 
y a la necesidad de distinguir, para las variantes sucesivas del texto impreso respecto al manuscrito definitivo, entre intervenciones atribuibles al autor (registradas evidentemente en las pruebas, hoy perdidas) o al tipógrafo.

Desde entonces estas soluciones se han adoptado y perfeccionado en otras ediciones proyectadas al socaire de la figura de Isella, gran promotor, sobre todo en los años de docencia en Pavía, de "talleres” de trabajo filológico: se ha rememorado el laboratorio de las rimas de Tasso, que Lanfranco Caretti había fundado en Pavía y que pudo contar con la colaboración de Luigi Poma, Cesare Bozzetti y Franco Gavazzeni, y el de Gadda, a los cuales se agregan el de Verga, con la participación, además de Cecco, de Carla Riccardi, y el de Manzoni con las ediciones, siempre en el ámbito de la universidad lombarda, del tratado Della lingua italiana de Luigi Poma y Angelo Stella (1974), de los Scritti linguistici e letterari de Luca Danzi y Angelo Stella (1991), y de los Scritti letterari editados por Carla Riccardi y Biancamaria Travi ${ }^{6}$, sin contar la de los Inni sacri realizada por Franco Gavazzeni y Simone Albonico ${ }^{7}$.

Del mismo modo, a la iniciativa de Isella se deben muchas colecciones que han publicado ediciones críticas de textos en varias redacciones de autor, como los "Classici Mondadori” (y luego los "Meridiani”), los "Studi e strumenti di filologia italiana" de la Fundación Arnoldo y Alberto Mondadori, la edición nacional de las obras de D’Annunzio y, en conclusión, la colección "Fondazione Pietro Bembo", que Isella creó con Giorgio Manganelli y que sigue activa bajo la dirección de Pier Vincenzo Mengaldo y Alfredo Stussi, colecciones en las cuales se han publicado importantes estudios procedentes también de otros centros de excelencia, afines en la investigación al método iselliano, empezando por la escuela de Domenico De Robertis.

Desde luego, más allá de este balance extremamente positivo para los estudios filológicos italianos, que sin duda están en la vanguardia sobre este particular sector de investigación, no se puede callar -y de esto se quejaba el mismo Isella en una aportación de 1999 ahora recopilada en la

6 Alessando Manzoni, Scritti letterari, ed. Carla Riccardi y Biancamaria Travi, Milán, Mondadori, 1991.

7 Alessandro Manzoni, Inni sacri, ed. Franco Gavazzeni y Simone Albonico, Milán, Mondadori, 1997. 
nueva edición de las Carte mescolate - que a menudo estas ediciones no han producido el debate y el crecimiento de los estudios que cabría esperar. Lo cual, por un lado, puede achacarse en parte a la estrecha trabazón entre ecdótica y crítica en ediciones caracterizadas por un armazón fuertemente interpretativo, que tal vez pueda provocar un efecto de momentánea "saciedad"; pero, por otro, parece que tiene que ver sobre todo con la dificultad para consultar aparatos a menudo extremamente complejos: problema que la adopción de unas normas compartidas en la medida de lo posible podría solucionar al menos parcialmente?

\section{I.3. LA FILOLOGÍA DE AUTOR EN LA ERA DIGITAL}

Desde los años treinta del siglo XX, con la introducción de la escritura a máquina, y luego desde los años setenta, con el uso generalizado de las fotocopias, la filología de autor ha tenido que enfrentarse a la entrada, en el proceso de producción-revisión-editing-impresión de los textos, de materiales de escritura y soportes distintos, y ha forjado nuevos criterios de representación de las correcciones (piénsese, por ejemplo, en las diferentes fases de enmienda representadas por las variantes manuscritas en un texto mecanografiado, los emparejamientos entre testimonios realizados con distintas máquinas de escribir, el uso del corrector blanco en los folios mecanografiados, los diferentes tipos de fotocopias que se pueden utilizar en la reconstrucción de series cronológicamente sucesivas de macrotextos, etc.; elementos, todos ellos, que caracterizan la filología del Novecientos) ${ }^{10}$.

Pero solo a partir de los años ochenta-noventa, con la introducción de la videoescritura, se ha asistido a una mutación radical de las formas de comunicación, generada por diferencias radicales en los procesos de ideación, escritura y revisión del texto digital respecto al manuscrito; algo

8 Dante Isella, Le carte mescolate vecchie e nuove, Turín, Einaudi, 2009, pp. 235-245.

9 Véanse, para la problematicidad de algunos aparatos, los ejemplos presentados por Alfredo Stussi en Introduzione agli studi di Filologia italiana (1994 y 2006).

10 Como puede verse en Paola Italia y Giulia Raboni, “3.6. L'opera di Carlo Emilio Gadda”, en Che cos'e la filologia d'autore, pp. 109-115. 
que podría parangonarse a la gran transformación constituida por la invención de la imprenta.

En este momento histórico, sin embargo, no nos hallamos todavía ante obras literarias enteramente pertenecientes al nuevo circuito productivo, ideadas, proyectadas, escritas y revisadas exclusivamente sobre un soporte digital, sino ante productos todavía de transición, obras literarias de una generación a caballo entre producción manuscrita y producción digital, y es importante no confundir los dos niveles.

Retomando el binomio que emplea felizmente Peter Shillingsburg (2006), una cosa es utilizar las nuevas tecnologías para realizar ediciones críticas de obras pertenecientes a la generación Gutenberg, y otra muy distinta es pensar una nueva filología para las obras de la generación Google.

From Gutenberg to Google es el título, en efecto, de un afortunado volumen que concierne justo a esta delicada fase de transición entre dos momentos históricos, en el cual Shillingsburg reflexiona sobre los criterios que pueden considerarse válidos para la edición científica de un texto en la $\operatorname{Red}^{11}$.

La gran cantidad de textos disponibles on line hace que resulte cada vez más urgente la definición de un protocolo para las ediciones de textos literarios de la era Gutenberg en la era Google, que permita constituir una plataforma común entre el editor crítico de textos, quien seguirá asumiendo la responsabilidad de establecer qué edición se debe presentar como texto (si bien en la red) y con qué características, y el lector, especialista o no, que podrá seleccionar las informaciones que brinda la infraestructura electrónica de acuerdo con sus intereses y con las preguntas que dirige al texto.

Desde este punto de vista no tiene mucho sentido hablar de la necesidad de una "nueva filología". Quien hoy aprende a leer y dentro de quince años descubrirá en la web el Quijote todavía podrá contar con la edición de Francisco Rico, sin que sea necesario instituir una nueva edición crítica del texto solo por el hecho de leerlo en la Red, y si quedara prendado de los versos del Canzoniere de Petrarca, podrá -tal vez con un programa construido con Just in Time Markup, JITM- descubrir la extraordinaria

11 Cf. Paola Italia, reseńa a "P. Shillingsburg, From Gutenberg to Google", Ecdotica, IV, 4 (2007), pp. 299-311. 
génesis de aquel texto a través de la edición del Codice degli abbozzi de Laura Paolino ${ }^{12}$. Situación muy diferente, en cambio, es la de los textos de la generación Google, es decir, de aquellos enteramente concebidos, proyectados, realizados y leídos (o escuchados) en la Red. Textos que ya no estarán hechos de papel sino de bytes y píxeles, y para los cuales de veras será preciso idear (pero esta tarea la acometerá la generación sucesiva a la nuestra) una nueva filología.

Veamos, en cambio, qué innovaciones ha conllevado la introducción de las tecnologías digitales, que han revolucionado, todavía en el ámbito de la "vieja" filología, la forma de trabajar del filólogo.

Un primer cambio significativo, en la fase de recopilación y estudio de los testimonios, consiste en la digitalización de los materiales manuscritos: junto a un examen directo del autógrafo, estos pueden estudiarse en la pantalla, superando los problemas históricos ligados tanto a la colocación de los testimonios (a menudo en archivos y bibliotecas muy distantes entre ellos) como a la calidad de la reproducción. Una foto digital de alta definición (que puede realizarse con una simple cámara digital) permite ampliar la imagen hasta diez veces su dimensión natural, girarla, modificar su color y contraste cromático e incluso, si se visualiza con programas específicos para el tratamiento de imágenes, leer debajo de una tachadura lo que a simple vista resulta indescifrable ${ }^{13}$. Las ediciones digitales, además, ofrecen la gran ventaja de poder archivar off line, y sobre todo on line, toda la documentación, manuscrita, mecanografiada e impresa relativa a un texto y brindarla al lector que, de manera mucho más fácil que en el pasado, puede seguir la reconstrucción del filólogo directamente en los documentos, y verificar así, concretamente, aquella hipótesis de trabajo que la edición crítica encarna.

Un segundo cambio en el trabajo del filólogo de textos de autor atañe a la fase de elaboración de la edición crítica, es decir, a la posibilidad, en la representación de la génesis y de la evolución del texto, de utilizar un soporte digital en lugar del papel. Los experimentos realizados en este

12 Cf. Paola Italia y Giulia Raboni, “3.1. Petrarca: il Codice degli abbozzi”, en Che cos’è la filologia d'autore, pp. 72-77.

13 Véanse las observaciones sobre el DVD de la reciente edición crítica que ha dirigido Gavazzeni en Paola Italia y Giulia Raboni, “3.5. Leopardi: los Canti”, en Che cos’è la filologia d'autore, pp. 99-109. 
sentido, más bien numerosos ${ }^{14}$, muestran las innumerables oportunidades que brindan las ediciones hipertextuales en la representación de la diacronía del texto y de las dinámicas de corrección. En efecto, la edición on line, a diferencia de aquella en formato papel, permite utilizar conexiones (links) internos o externos a la edición, y marcadores cromáticos para representar las varias estratificaciones del texto o fases distintas de corrección: elementos, estos, que en la edición de papel, como veremos, se confiaban a los marcadores tipográficos (monocromáticos) y al empleo de símbolos y abreviaciones.

También en este caso la gran cantidad de informaciones archivables en la Red permite superar las dificultades propias del soporte de papel, que obligaban al filólogo a tener en cuenta también unos criterios de economía en la representación del aparato. Lo cual no quiere decir que las nuevas ediciones deban ser repetitivas y redundantes, sino, por ejemplo, que ante testimonios muy diferentes entre ellos, precisamente la gran disponibilidad de espacio para archivar y la facilidad de cotejo sinóptico inducen a privilegiar las multiplicaciones de los testimonios antes que la reducción a la relación (a menudo en absoluto sencilla) entre texto y aparato ${ }^{15}$.

La tecnología digital produce grandes ventajas en la fruición de las ediciones críticas, tanto a nivel de aprendizaje didáctico como de estudio especializado, debido a la inmediata disponibilidad de las ediciones realizadas on line, que pueden visualizarse y estudiarse o -si está permitido- incluso descargarse en el propio ordenador. No debemos olvidar que la filología de autor siempre ha sido coto de una producción editorial alta, muy elegante (también por las refinadas técnicas tipográficas utilizadas), a la vez que muy costosa, y esa mayor fruición de los instrumentos de estudio constituye una auténtica revolución democrática.

Otra ventaja estriba en la disponibilidad y en la facilidad de consulta de ediciones realizadas en el ámbito internacional, que llevan a la filolo-

14 Cf. Paola Italia y Giulia Raboni, "Risorse in Rete di filologia d'autore", en Che cos’è la filologia d'autore, pp. 126-127.

15 Según demuestra la solución del problema filológico del Fermo e Lucia; cf. Paola Italia y Giulia Raboni, "3.4. Manzoni: il Fermo e Lucia e la Seconda minuta", en Che cos’è la filologia d'autore, pp. 90-99. 
gía de autor italiana a confrontarse con las técnicas de representación y estudio de las variantes autoriales elaboradas en otros países, no solo europeos, poniendo en marcha así un virtuoso círculo de comunicación capaz de romper el aislamiento en que ha vivido esta disciplina, y permitiendo a la comunidad científica internacional la elaboración de protocolos y técnicas de representación cada vez más compartidos: verdadero fundamento de un método científico.

Finalmente, las últimas fronteras de la web, representadas por el uso de plataformas de trabajo e intercambio de informaciones (web 2.0 ), constituyen una auténtica innovación metodológica, superando las distancias geográficas entre los estudiosos, que pueden confrontarse directamente entre ellos y compartir los contenidos y los espacios virtuales de las varias plataformas en tiempo real, en una especie de seminario permanente. Una manera de trabajar nueva, a escala global, con extraordinarias potencialidades ${ }^{16}$, que modificará cada vez más el trabajo del filólogo, haciendo que pase de una dimensión individual (cuando no solipsista) a compartir el saber con toda una comunidad científica.

\section{MÉTodos}

\section{I. El texto}

Como hemos dicho, la filología de autor se ocupa de la edición del original, es decir, del manuscrito redactado directamente por el autor (autógrafo) o redactado bajo su directa supervisión por una mano diferente (idiógrafo), además de las versiones impresas que ha preparado el mismo autor. Sin embargo, pueden presentarse casos muy distintos, cada uno de los cuales con problemáticas difícilmente resumibles en un enfoque general. De forma esquemática se pueden dividir las competencias de la filología de autor en dos categorías fundamentales: la edición de textos in

16 Véase el experimento gaddiano http://www.filologiadautore.it/wiki; cf. Paola Italia y Giulia Raboni, “3.6. L'opera di Carlo Emilio Gadda”, en Che cosè la filologia d'autore, pp. 109-115. 
fieri, para la cual Segre ${ }^{17}$ habla con mayor exactitud de crítica genética, y aquella de textos en varias redacciones (a la que pertenece propiamente la crítica de las variantes).

\section{I.I. Edición de textos in fieri}

El texto está documentado por un manuscrito único, autógrafo o idiógrafo, que puede ser una copia 'en limpio' o presentar huellas más o menos consistentes de elaboración. En el caso del manuscrito en limpio nos hallamos en definitiva con la misma fenomenología -en el ámbito de la filología de la copia- de la edición de un texto transmitido por un único testimonio; aunque sea naturalmente distinta la situación del autógrafo, que representa directamente los usos gráficos y fonéticos del autor, respecto a la del idiógrafo, donde la mediación del copista puede haber introducido innovaciones o normalizaciones ajenas al uso del autor. Constituye, además, un problema particular el caso de los errores presentes incluso en autógrafos, sobre todo cuando el autor es el copista de sí mismo, es decir, cuando copia sus textos a partir de un traslado anterior. Sobre este argumento existen posiciones diferentes que oscilan desde el absoluto respeto del texto autógrafo hasta la corrección de lo que puede considerarse una banal errata. Al margen de la decisión tomada, es necesario señalar con precisión la intervención redaccional. En cambio, si el manuscrito único presenta variantes, el filólogo tendrá que establecer el texto y de sus decisiones derivará el tipo de aparato utilizado para representar dichas variantes.

A la pregunta “QQué lección elegir para el texto?” podrá dar una doble contestación. De hecho, podrá optar por transcribir la lección base (o sea, la primera redacción del texto) y representar en el aparato las variantes introducidas sucesivamente, desde la primera hasta la última (aparato evolutivo), o, en cambio, elegir el texto de la última lección reconstruible en el manuscrito y representar en el aparato las correcciones a través de las cuales ha llegado a la versión final, desde la última hasta la primera (aparato genético). Como veremos, este último procedimiento también puede

17 Franco Gavazzeni y Clelia Martignoni, “Dante Isella e la filologia d'autore. Atti della giornata di studi”, Strumenti Critici, 120 (2009), pp. 203-208. 
representarse de forma progresiva, reconstruyendo el itinerario desde la lección inicial hasta la final (que se lee en el texto).

Un caso complejo es el de los textos inconclusos, para los cuales hay que tomar decisiones particularmente delicadas, sobre todo si se trata de redacciones que no hayan experimentado una revisión definitiva.

\section{I.2. Edición de textos en varias redacciones}

Es muy diferente, por supuesto, la situación de una obra que presenta más redacciones de autor (manuscritas y / o impresas). En este caso la primera y fundamental pregunta que hay que hacerse es si se trata de redacciones confrontables. Si se pueden cotejar, la elaboración completa puede representarse en un aparato relativo al único estadio redaccional que reproduce el texto editado. Pero se puede decidir ofrecer un texto para cada estado redaccional, cada uno con sus propias variantes internas, creando un aparato "de ajuste" que establezca una conexión entre el último estadio al que ha llegado cierta elaboración anterior y la sucesiva, cuando no es posible un careo entre versiones profundamente distintas (como para el tríptico de Manzoni constituido por Fermo e Lucia / "Segundo Borrador" / edición llamada Ventisettana), o cuando así lo prefiere el editor por razones de estudio (como para los Canti de Leopardi en la edición de Gavazzeni).

Naturalmente las situaciones pueden ser más o menos complejas: es posible que el autor retome sus manuscritos en momentos diferentes, vuelva a utilizar partes de una redacción precedente, trabaje paralelamente en redacciones diversas (hoy día pueden darse casos así gracias al uso de fotocopias o de impresiones de archivos informáticos), o incluso es posible que el original se pierda, pero que se conserve su lección en la tradición derivada: situación en la cual la filología de autor y la filología de la copia tienen que cooperar para discernir errores de la tradición y variantes de autor. Hace falta reconocer, pues, la categoría ante la cual nos hallamos y tomar decisiones justificadas tanto desde un punto de vista histórico-cultural, cuanto desde la perspectiva de la máxima economía de la representación, además de la facilidad de lectura de texto y aparato. 
Estas primeras observaciones permiten colegir en qué medida la operación de elección del texto resulta muy delicada y cuáles son sus importantes repercusiones no solo en el plano estrictamente ecdótico, sino también en el literario y, más en general, cultural.

\subsection{3. ¿La última voluntad del autor?}

Veamos un ejemplo concreto. Supongamos que un autor haya publicado un texto unas cuantas veces y en diferentes lugares. Si una editorial nos encargara la preparación de una edición moderna de dicho texto, ¿qué impresión deberíamos preferir? ¿La primera edición, la segunda, la tercera o la última? La elección no es tan sencilla.

En la práctica, hasta el siglo pasado se consideraba necesario publicar el texto que reflejara "la última voluntad del autor»; en consecuencia, en este caso deberíamos elegir la última edición que el autor ha publicado. Pero en los últimos años han empezado a oírse algunas objeciones en contra del concepto de "última voluntad del autor», y se ha puesto así en tela de juicio aquella communis opinio que antes lo veneraba como si fuera una especie de dogma.

Para afrontar las diferentes facetas de este problema es preciso distinguir dos planos:

1) los elementos a favor o en contra de la adopción de la «última voluntad del autor» para fijar el texto de referencia;

2) los criterios que se deben seguir, una vez establecido el texto, para respetar (o no) la "última voluntad del autor" por lo que concierne a cada lección individual.

Creemos, en efecto, que se tienen que afrontar separadamente los dos momentos en los cuales el editor se mide con la «última voluntad del autor», es decir, con la configuración textual de la obra publicada y la intervención sobre las lecciones adoptadas ${ }^{18}$.

La primera faceta atañe a la idea de sí mismo y de su obra que el autor ha manifestado (o no) en el transcurso de su existencia a través de un

18 Sobre estos problemas, cf. Paola Italia, "L'ultima volontà del curatore. Considerazioni sull'edizione dei testi del Novecento (I e II)", Per Leggere, V, 8-9 (2005), pp. 191-233 y 169-98. 
programa editorial, realizado o solo imaginado, y la forma en la cual la ha entregado definitivamente a sus lectores. La elección textual del editor es muy delicada porque concierne a esa nueva imagen del autor y de la obra que necesariamente la nueva edición fabricará. Escriben Bruno Bentivogli y Paola Vecchi Galli sobre el papel del editor en las ediciones del siglo XX: "Le corresponde al filólogo determinar la estrategia editorial más adecuada para el texto, anteponiendo, por medio del mismo acto de la publicación, la fuente más autorizada: esta, a su vez, podrá no identificarse con la forma definitiva, sino con la fase del libro más "militante" o «innovadora» para los lectores" ${ }^{19}$.

El segundo plano atañe, en cambio, a la práctica editorial respecto a las lecciones individuales, y también a problemas de talante lingüístico, gráfico, tipográfico, relativos a la lengua y al estilo del autor examinado, aunque en cierta medida se puedan generalizar. Las diferentes ediciones científicas realizadas durante el último siglo presentan una tipología de intervenciones muy variadas, con muchas discrepancias entre una y otra edición, pero también con algunos elementos constantes que pueden inducirnos a confiar en que algún día la comunidad científica llegue a una reglamentación.

En la presentación del problema seguimos el enfoque de Stussi ${ }^{20}$, el primero en escudriñar los argumentos a favor y en contra de cada elección. Los argumentos que sustentan la «última voluntad del autor», es decir, el rescate moderno de la última impresión publicada mientras el autor vivía, hacen hincapié generalmente en tres motivaciones:

1) motivación autorial: invoca el acatamiento de las elecciones personales del autor, un «sentimiento común tan difundido que se impone fácilmente incluso en ámbito editorial $»^{21}$. Desde esta perspectiva la «última voluntad» parece entregar a los lectores una obra «más verdadera»;

2) motivación histórica: sostiene que el enfoque diacrónico, que brinda la última lección de una obra, permite reconstruir mejor la historia del texto, insertándolo en un itinerario histórico. Desde este punto de vista la «última voluntad» parece entregar al lector una obra «más útil» para comprender al autor y su misma obra;

19 Bruno Bentivogli y Paola Galli, Filologia italiana, Milán, Mondadori, 2002, p. 163. 20 Alfredo Stussi, Introduzione, 2006.

21 Ibidem, p. 191. 
3) motivación crítico-evolucionista: si, al pasar de la forma primigenia a la final, la obra llega a un estadio más evolucionado, entonces el juicio crítico favorecerá implícitamente la última impresión respecto a las anteriores. Desde esta perspectiva, la "última voluntad" parece entregar al lector una obra "más válida".

Pero es posible dar la vuelta a estos argumentos a favor, con otros tantos de signo opuesto:

1) motivación autorial: no siempre la última voluntad refleja el pensamiento más genuino del autor; sería suficiente pensar, según recuerda Stussi, en las "restricciones al ejercicio de esa voluntad por lo que atañe a la línea sucesoria" o en el caso de una "manifiesta alteración mental, constricción, etc." (ibidem) ${ }^{22}$. La primera edición se impone por el valor que le atribuye el mismo autor, que confía a ella la idea de sí mismo y de su obra;

2) motivación histórica: la perspectiva histórica se valora mejor examinando el itinerario en sentido diacrónico, desde la primera impresión hasta la última, y solo el cotejo entre ellas nos puede brindar informaciones históricamente verificables sobre la lengua y el estilo de la obra, la cual, en caso contrario, se achata en la imagen sincrónica final. Además, la primera edición permite valorar mejor la "recepción crítica" de la obra y reconocer su "tradición», es decir, su fuerza de impacto dentro del sistema literario;

3) motivación critico-evolucionista: la presunta evolución hacia una forma mejor de la obra es una mistificación; en efecto, no siempre la última edición es la mejor y, al contrario, el valor primigenio de una obra se reconoce mejor en la primera impresión que «representa, de costumbre, la conclusión del proceso creativo originario de una obra y, en consecuencia, el resultado de la fase productiva más intensa de un escritor» ${ }^{23}$.

Como es fácil de ver, la cuestión puede enfocarse tanto en pro cuanto en contra de una u otra solución, según los casos. De ello se colige una especie de "pirronismo filológico", poco distante del "agnosticismo de la sedicente New Philology"24, que no tolera textos críticos y aparatos, al considerarlos elementos "accesorios" del texto (opinión que el párrafo siguiente intentará desmentir).

22 Ibidem, p. 191.

23 Ibidem, p. 192.

24 Alfredo Stussi, Introduzione, 1994, p. 292. 
Conforme ha escrito Paolo Cherchi, a propósito del debate suscitado por la New Philology, los focos de discusión son esencialmente dos: la dialéctica entre "texto" y "obra" ("La autoridad de la filología ha acabado por crear cierta confusión entre "texto" y «obra»; así que nos sentimos incómodos cuando leemos una obra cuyo texto presenta lecciones inciertas, aunque durante siglos no hayamos hecho otra cosa sino leer "obras»"25); y, en segundo lugar, las relaciones entre filología e italianística: porque la perspectiva de desarrollo tanto de una filología (románica) que pretende renovarse con un acercamiento a la historia de la cultura, cuanto de una italianística que quiere aproximarse al comparatismo, además de contribuir a hacer menos rigurosa la disciplina -como no es infrecuente observar incluso en ediciones de cierto prestigio- $y$ de no permitir una reflexión común sobre los métodos y sobre las finalidades del trabajo filológico, es absolutamente falsa. Basta pensar que no existe todavía una convención general en la comunidad científica ni sobre la terminología adoptada ni para la representación de las correcciones y de las variantes de autor (con una proliferación antieconómica de signos y abreviaciones). Ante cualquier nueva edición crítica, el lector tiene que aprender cada vez un nuevo sistema de representación (con símbolos, siglas, abreviaciones diferentes), lo cual constituye el primer obstáculo para un debate abierto dentro de la misma comunidad.

Es verdad que la reflexión sobre estos temas y sobre las decisiones ecdóticas tomadas tiene consecuencias importantes para la recepción del texto y, en consecuencia, para su interpretación. Analicemos, entre muchos otros, el caso de Ungaretti.

La situación de los poemas de Ungaretti es emblemática y representativa de una última voluntad del autor que se ha manifestado en etapas diferentes, pero que se ha concretado definitivamente en dos ediciones omnicomprensivas de su obra que constituyen (o han constituido hasta ahora) el ne varietur de la tradición textual de la producción ungarettiana: el largo y atormentado recorrido variantístico iniciado con los dos poemarios L'Allegria (del cual disponemos hoy de una edición crítica, preparada por Cristina Maggi Romano, Milán, Fondazione Arnoldo e Alberto Mondadori, 1982) y Sentimento del tempo (edición crítica de Ro-

25 Paolo Chechi, "Filologie del 2000”, Rassegna Europea di Letteratura Italiana, 17 (2001), pp. 135-53. 
sanna Angelica y Cristina Maggi Romano, Milán, Fondazione Arnoldo e Alberto Mondadori, 1988), termina con la edición mondadoriana del 1942-45, que el mismo autor proyectó y supervisó.

Esta consta de tres volúmenes, de los cuales los dos primeros se asignan a los poemarios mencionados, mientras que el último se dedica a los Poemas dispersos y está provisto, por voluntad del autor, de un dossier de las variantes de imprenta preparado y comentado por Giuseppe De Robertis. Un caso excepcional en que el mismo autor, director no oculto de toda la operación, entrelaza estrechamente tradición textual y crítica.

La edición definitiva de Vita d'un uomo. Tutte le poesie, preparada en 1969 (Milán, Mondadori, con una puesta al día en 1970) por Leone Piccioni cuando todavía vivía el autor, recopila los dos principales poemarios en la forma editorial de 1942-45 (aunque con mínimos retoques posteriores del autor) y añade las últimas ediciones de Il Dolore, La Terra Promessa, Un Grido e Paesaggi, Il Taccuino del vecchio, Dialogo, Nuove, Dernier Jours y los Poemas dispersos (es decir, los textos publicados entre 1915 y 1927 y no incluidos en las ediciones definitivas de Allegria y Sentimento del tempo), mientras que en una sección diferente de Otros poemas hallados se recuperan siete textos. En la "Nota al texto" de Allegria, de puño y letra del autor, figura la significativa declaración: "Como el zorro pierde el pelo pero no las mañas, el autor, aunque había llamado definitivas a las susodichas ediciones, no ha podido resistirse, en cada nueva ocasión, a algún retoque formal" 26 .

Diferente, respecto a lo que proyectó Ungaretti en Vita d'un uomo, es la decisión de las editoras de las dos ediciones críticas de 1982 (L'Allegria) y 1988 (Sentimento del tempo), que como texto base no eligen el de la edición mondadoriana de 1942-45, reproducido en los tres "Meridiani", sino, respectivamente, la segunda edición Vallecchi de 1919 de Allegria (más representativa que la princeps de 1916 del itinerario literario de la obra) y la redacción inicial de cada composición para el Sentimento del tempo, según lo ilustrado por Domenico De Robertis en la $N$. d. D. (Nota del Director) de 1990, con la motivación de que el proceso de elaboración del poemario se despliega por completo antes de la princeps de 1933 (a raíz de la cual se registran solo incrementos textuales), y que por tanto

26 Giuseppe Ungaretti, "Note" a Vita de un uomo. Tutte le poesie, Milán, Mondadori, 1969, p. 528. 
la historia del Sentimento del tempo no podía representarse sino "a través del paciente examen total de la evolución de los textos individuales hasta su cristalización de 1933 "27. En las justificaciones de estas decisiones y en las objeciones que, incluso recientemente, han suscitado, estriba el meollo de la crisis del concepto de última voluntad del autor.

$\mathrm{El}$ abanico de propuestas alternativas formuladas por estas ediciones críticas sintetiza adecuadamente la delicada cuestión de la fijación textual por parte del editor. Limitándonos solo a la Allegria, se contraponen la elección de V, es decir, la edición Vallecchi de 1919 (solución de Maggi Romano-De Robertis), la vuelta a U, o sea el Porto sepolto publicado en Udine en 1916, según sostienen Ossola (Nota a Ungaretti, 1990), quien propone el empleo de las variantes evolutivas en el comentario "subordinando el esprit de système filológico al acto de la interpretación crítica" ${ }^{28}$, y Sereni y Ossola ${ }^{29}$, reclamando que una edición crítica examine tan solo la tradición impresa: solución ya adoptada por la mondadoriana de 1945, si bien esta "no puede definirse como una edición crítica" (según nos recuerda $V_{e l a}{ }^{30}$ ), y -finalmente- la "última voluntad" de M (Mondadori,1942-45), en la solución que recomienda Claudio Giunta ${ }^{31}$ sobre la base del "prestigio histórico del testimonio", "ligado por un lado a la "forma" excepcional de la impresión mondadoriana del $42(\mathrm{M})$ y, por otro, a los reflejos que aquella forma irradió sobre la sucesiva actividad ungarettiana" (solución aplicada, cuando aún vivía Ungaretti, por los responsables de la edición definitiva de Vita d'un uomo. Tutte le poesie de 1969 , pero propuesta por Giunta ${ }^{32}$ con la "multiplicación de los individuos textuales": de cada testimonio "la primera redacción publicada en volumen"). Estas decisiones encontradas permiten medir la vivacidad y la importancia de un debate todavía abierto.

27 Giuseppe de Robertis, "N. d. D. [Nota del directore]", Studi di Filologia Italiana, 48 (1990), p. 306.

28 Claudio Giunta, "Prestigio storico dei testimoni e ultima volontà dell'autore", Anticomoderno, 3 (1997), p. 174.

29 Umberto Sereni y Carlo Ossola, "L'atto di Lucifero: Ungaretti apuano", Lettere Italiane, XLII (1990), pp. 388-413.

30 Claudio Vela, La letteratura del Novecento, en Storia della letteratura italiana, dir. Enrico Malato, vol. X. La tradizione dei testi, Roma, Salerno, 2001, cap. XXVIII, p. 1276.

31 Claudio Giunta, op. cit., p. 175.

32 Ibidem, pp. 183-184. 
Por lo tanto, antes de emprender un estudio crítico interpretativo será necesario preguntarse: “QQué texto leemos cuando leemos un texto?”.

\subsection{El aparato}

\subsection{Aparato genético y aparato evolutivo}

Si el aparato, como hemos visto, es la concreta aplicación de la hipótesis representada por el texto, se colige que, dependiendo de la decisión que tomemos acerca del texto, tendremos un tipo consecuente de aparato. En particular, come se ha dicho, tal elección resulta ligada estrechamente a nuestra decisión de fijar (o no) como texto la última voluntad del autor y de presentar el recorrido correccional del texto de manera genética o de manera evolutiva.

Los aparatos, en efecto, de acuerdo con la puntual definición de Isella ${ }^{33}$ se distinguen en genéticos y evolutivos. ¿Qué diferencia media entre unos y otros?

El aparato genético es una representación gráfica de las enmiendas que se han depositado sucesivamente en un texto manuscrito (o en uno impreso con correcciones manuscritas, o incluso, en el caso de obras del XX, en un texto mecanografiado con correcciones manuscritas); en otras palabras, es un sistema que refleja de forma sintética y estandarizada la génesis del texto, desde su primera redacción hasta la que juzguemos que pueda representar la última forma completa, que decidimos reproducir como texto. Cada aparato genético -como se ha dicho- no es una fotografía del texto, sino una hipótesis del estudioso en torno a las modalidades y a los tiempos de su elaboración.

El aparato evolutivo registra, en cambio, las variantes sucesivas al estadio que hayamos decidido reproducir como texto, es decir, las que pertenecen no a una fase de génesis de lo que todavía debe transformarse en texto, sino a la evolución de lo que ya se ha fijado como tal. El aparato evolutivo no es siquiera una reproducción fiel del estado del manuscrito, sino solo la interpretación que propone el filólogo de la evolución del texto, desde la fase documentada por el texto editado hasta la última lección deducible del mismo manuscrito.

33 Dante Isella, Le carte mescolate vecchie e nueve, p. 100. 
De donde se deduce que, en una edición crítica, la presencia de un aparato genético o evolutivo depende solo de lo que el editor crítico ha decidido fijar como texto (véase la tabla siguiente). Si el texto es la última redacción, el aparato de las correcciones será genético; si, en cambio, es la primera redacción, el aparato será evolutivo; si, finalmente, es una redacción intermedia (por ejemplo, la lección base de la copia en limpio del texto, antes de que sobre ella se depositen nuevas enmiendas), el aparato de las variantes será en parte genético (todas las correcciones que conducen a la lección establecida como texto) y en parte evolutivo (las correcciones que arraigan en el mismo texto para modificarlo ulteriormente).

TABLA Texto y aparato

\begin{tabular}{l|l} 
Tехто & Aparato \\
\hline Última lección reconstruible & Genético \\
\hline Primera lección reconstruible & Evolutivo \\
\hline Lección intermedia & Genético / evolutivo
\end{tabular}

Si el texto corresponde a una redacción que no es la última que el manuscrito permite reconstruir, porque alberga ulteriores correcciones, las situaciones que se pueden presentar son dos: las variantes desembocan o no desembocan en un texto acabado.

El segundo caso lo analiza Isella a propósito del Mattino de Parini, en el cual, entre la primera y la segunda redacción, que obedecen a dos lógicas constructivas muy diferentes, se sitúa un ensayo intermedio de corrección de la redacción inicial que no sigue -sin embargo- el rumbo tomado por la redacción sucesiva, sino que pertenece a una fase transitoria, luego abandonada, y experimentada solo fugazmente. Aquí el editor no tiene elección, porque corre el riesgo de confundir fases redaccionales distintas: tiene la obligación de representar estas variantes en un aparato evolutivo respecto a la primera redacción. Pero, en general, las revisiones llevan a un resultado, al menos provisionalmente estable, que puede alcanzarse o dentro del mismo testimonio, configurándose, en consecuencia, como revisión global de la misma fase, o «compelen» en un cierto momento a una reescritura, confiada de costumbre a un nuevo testimonio: en este caso la elección entre un aparato genético o uno evolutivo queda abierta y subordinada a los criterios de edición. 
Pongamos un ejemplo concreto. Tomemos el manuscrito del más célebre poema de Leopardi, el Infinito (en la redacción del llamado "Cuaderno Napolitano", conservado en la Biblioteca Nacional Vittorio Emanuele III de Nápoles, C.L. XIII.22). Si observamos el texto podemos notar que algunos versos han sido enmendados con una pluma, al parecer diferente respecto a la que Leopardi usó para la redacción base del texto (cf. Lámina 1).

Si quisiéramos publicar el texto de este manuscrito leopardiano tendríamos dos posibilidades:

1) publicar el texto correspondiente a la «última voluntad del autor», que vale tanto como decir que brindamos la transcripción de la última lección que el manuscrito permite colegir;

2) publicar el texto correspondiente a la primera redacción, es decir, ofrecer la transcripción de la primera lección completa que el manuscrito permite inferir.

Veamos en concreto las dos posibles soluciones y sus consecuencias en los relativos aparatos.

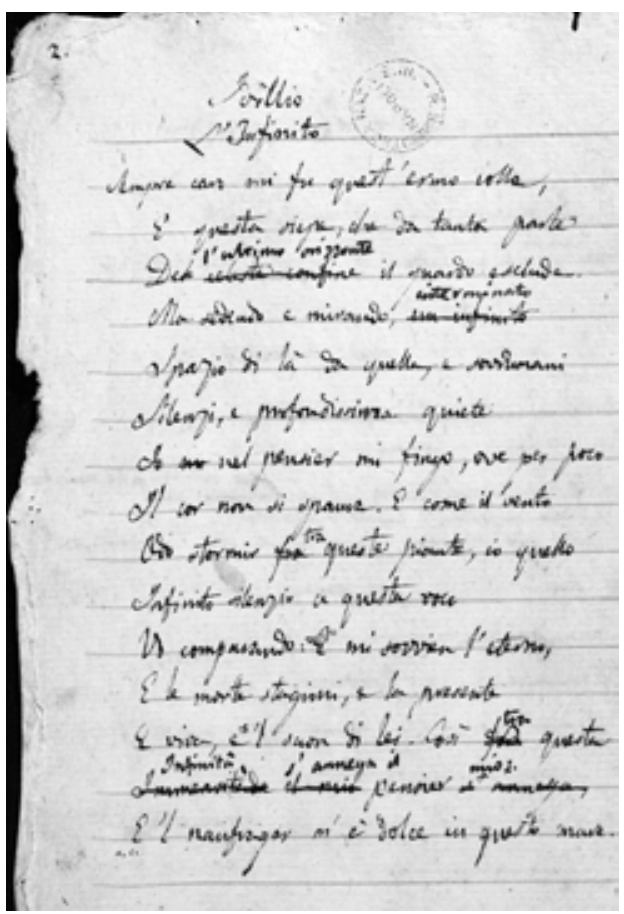

1. Giacomo Leopardi, LIInfinito (C.L. XIII. 22, p. 2) 


\section{Texto correspondiente a la "última voluntad del autor"}

\section{Idillio \\ L'Infinito}

1 Sempre caro mi fu quest'ermo colle,

2 E questa siepe, che da tanta parte

3 De l'ultimo orizzonte il guardo esclude.

4 Ma sedendo e mirando, interminato

5 Spazio di là da quella, e sovrumani

6 Silenzi, e profondissima quiete

7 Io nel pensier mi fingo, ove per poco

$8 \quad$ Il cor non si spaura. E come il vento

9 Odo stormir tra queste piante, io quello

10 Infinito silenzio a questa voce

11 Vo comparando: e mi sovvien l'eterno,

12 E le morte stagioni, e la presente

13 E viva, e 'l suon di lei. Così tra questa

14 Infinità s'annega il pensier mio:

15 E'l naufragar m'è dolce in questo mare.

Hemos destacado en negrita las palabras del texto involucradas en las variantes (tanto las variantes inmediatas como las tardías, cf. $\$ 2.3 .1$ ). Si esta es la lección fijada como texto, se deduce que el aparato será de tipo genético e intentará representar las correcciones realizadas desde la primera hasta la última redacción.

2. Texto correspondiente a la lección base (primera redacción del texto)

\section{Idillio \\ L'Infinito}

1 Sempre caro mi fu quest' ermo colle,

2 E questa siepe, che da tanta parte

3 Del celeste confine il guardo esclude.

4 Ma sedendo e mirando, un infinito

$5 \quad$ Spazio di là da quella, e sovrumani 


$\begin{array}{ll}6 & \text { Silenzi, e profondissima quiete } \\ 7 & \text { Io nel pensier mi fingo, ove per poco } \\ 8 & \text { Il cor non si spaura. E come il vento } \\ 9 & \text { Odo stormir fra queste piante, io quello } \\ 10 & \text { Infinito silenzio a questa voce } \\ 11 & \text { Vo comparando. E mi sovvien l'eterno, } \\ 12 & \text { E le morte stagioni, e la presente } \\ 13 & \text { E viva, e 'l suon di lei. Così fra questa } \\ 14 & \text { Immensitade il mio pensier s'annega, } \\ 15 & \text { E'l naufragar m'è dolce in questo mare. }\end{array}$

Si esta es la lección fijada como texto, se infiere que el aparato será de tipo evolutivo, ya que intentará representar las correcciones realizadas sobre el texto desde la lección base hasta la última lección que el manuscrito permite reconstruir.

La misma distinción vale, por supuesto, también en el caso de diferentes versiones impresas, o de tradición mixta (manuscritos e impresos): cuando es posible carear las redacciones, y estas no requieran, por tanto, una edición autónoma, el editor puede decidir si brindar como texto la última redacción y en consecuencia recoger el proceso elaborativo precedente en un aparato genético, o, por el contrario, representar como texto la primera versión, recogiendo la elaboración sucesiva en un aparato evolutivo.

Veremos más adelante de qué modo se pueden ilustrar sintéticamente dichas correcciones, explicándolas no con palabras sino con abreviaciones y símbolos para representar categorías semejantes de correcciones. Veremos, dicho de otro modo, cómo concretamente se fabrica un aparato (genético o evolutivo). Pero ahora nos tenemos que ocupar, ante todo, de los criterios generales para la representación de las variantes.

\subsubsection{Aparato vertical y horizontal}

La representación de las variantes puede hacerse de dos maneras: con un aparato vertical, también definido como "representación en columna" 34 o con un aparato horizontal, también llamado "representación linear" 35.

34 Alfredo Stussi, Introduzione, 2006, p. 187.

35 Ibidem, p. 189. 


\subsubsection{Aparato vertical o en columna}

En este tipo de aparato se colocan en una columna y se representan verticalmente todas las correcciones de un verso, desde la primera hasta la última, indicando con marcadores tipográficos oportunamente elegidos (cursiva, negrita) las tachaduras que han llevado a la escritura de una nueva lección o a las inserciones de nuevas porciones de texto.

El texto de referencia puede ser el último reconstruible a partir del manuscrito o el primero, y es posible señalarlo con ulteriores marcadores tipográficos; además, se puede reproducir integralmente en la misma página donde figura el texto en columna o colocarlo al principio de la edición, como punto de llegada o de arranque, para que se lea de seguido. La verticalidad coincide con la temporalidad; los versos o las porciones de verso no sujetas a variación, no se repiten, para que así sea inmediatamente evidente dónde y cómo se arraiga la corrección.

Es patente que este tipo de aparato se puede adoptar exclusivamente para textos poéticos, ya que el verso no excede la dimensión de una línea tipográfica y consiente la disposición en columna de las variantes en las líneas siguientes, solución impracticable para un texto en prosa.

Este modelo de aparato se utilizó por primera vez para los Canti de Leopardi en la edición de Moroncini de 1927, y se ha aplicado para otras importantes ediciones de textos poéticos. Su gran ventaja estriba en el hecho de que no es preciso hacer referencia continuamente al texto para seguir su génesis, puesto que texto y aparato no están separados, sino que el ojo sigue directamente la evolución del texto; la desventaja consiste en el hecho de que no se tiene la posibilidad de leer de seguido el texto sin sus correcciones, a menos que este no se reproduzca separadamente (antes de la edición crítica, como hizo Moroncini para los Canti de Leopardi), o en una sección en lo alto de la página (como hizo Peruzzi en una sucesiva edición crítica de los Canti) ${ }^{36}$.

No se debe olvidar, sin embargo, otra desventaja, menos evidente pero decisiva, que imposibilita a este tipo de formalización su funcionalidad

36 Véanse Paola Italia y Giulia Raboni, “3.5. Leopardi: los Canti”, en Che cos’e la filologia d'autore, pp. 99-109. 
para comprender la evolución de las fases del texto. Señalando las correcciones individualmente para cada verso, este aparato impide vislumbrar los nexos entre correcciones que afectan a unidades sintácticas de dimensiones mayores, y que rebasan la medida de un verso (hecho muy común en la poesía, donde la unidad entre verso y medida métrica es más bien una excepción que una regla).

Considérese otro ejemplo, mostrado en la lámina 2, que igualmente deriva del "Cuaderno Napolitano" de los Idilli de Leopardi (el texto es el de La vita solitaria, C.L. XIII.22, c. 15).

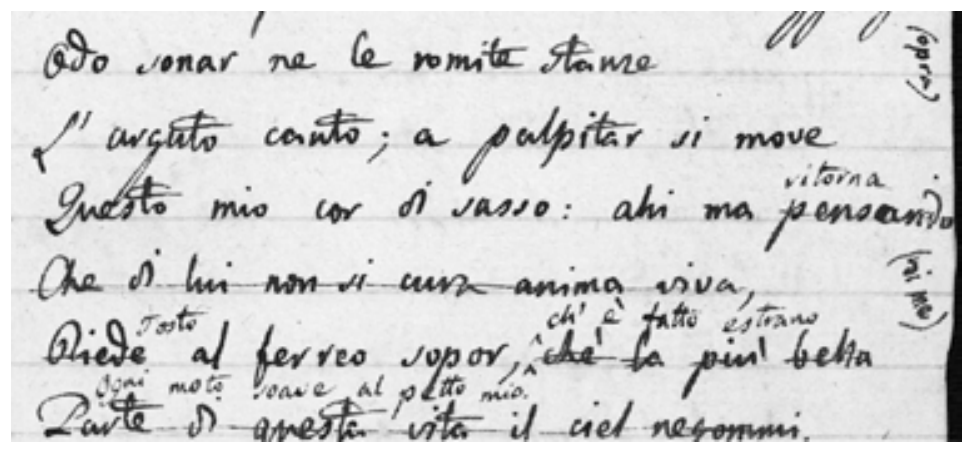

2. Giacomo Leopardi, La vita solitaria (C.L. XIII.22, c. 15)

La representación en columna de las enmiendas en los vv. 64-68, si se ofrecen verso a verso, impide ver el nexo sintáctico entre la verdadera corrección, que se coloca entre el v. 66 ("ritorna”) y el v. 67 ("riede") -aquí transcritos en negrita- porque "pensando" parece corregido como "ritorna" y "riede" parece enmendado como "tosto":

64 Odo sonar ne le romite stanze

65 L'arguto canto; a palpitar si move

66 Questo mio cor di sasso: ahi ma pensando

\section{ritorna}

67 Che di lui non si cura anima viva,

Riede al ferreo sopor, chè la più bella

Tosto

ch'è fatto estrano 
68 Parte di questa vita il ciel negommi

Ogni moto soave al petto mio.

\subsubsection{Aparato horizontal o linear}

El aparato horizontal, en cambio, distingue entre texto y aparato, que se separan topográfica y gráficamente. En la parte superior del folio se halla el texto, mientras que en la inferior, en una sección al pie de página, se encuentra el aparato, donde se enumeran consecutivamente las variantes. Al contrario del aparato en columna, en el cual la verticalidad representa la temporalidad, en este tipo de aparato la temporalidad se representa horizontalmente. El punto de anclaje en el texto se señala con una porción del mismo texto reproducida en el aparato, seguida de un corchete y, a continuación, de la variante (todo lo que precede al corchete, por tanto, coincide con la lección del texto).

A dicho esquema pueden añadirse otros elementos, desde las fases de elaboración, señaladas con un número o una letra alfabética, hasta las abreviaciones que indican la topografía de las variantes, o signos diacríticos, o bien cuerpos tipográficos diferentes, para distinguir cronológicamente las mismas variantes. La secuencia de las correcciones puede cerrarse con una $\mathrm{T}$, signo que indica que la cadena de enmiendas se termina con lo que se lee en el texto (veremos analíticamente en el apartado $\$ 2.5$ las abreviaciones más comunes y los signos diacríticos más usados).

El inconveniente de este tipo de aparato estriba en la necesidad de remitir continuamente al texto que figura en la parte superior para poder seguir las correcciones. El defecto se acentúa aún más cuando, como desafortunadamente sucede con cierta frecuencia, por razones editoriales el aparato se relega al final del volumen y no se coloca, como en cambio sería más útil, al pie de la página, debajo del texto. Sin embargo, puede ocurrir, cuando el aparato es sumamente complejo, que se imprima en un volumen separado (como en el caso de la edición crítica del Fermo e Lucia $\left.^{37}\right)$.

La ventaja, al margen de la mayor familiaridad de los estudiosos con una representación que separa texto y aparato, consiste en que este apa-

37 Cf. el apartado 3.4. 
rato puede utilizarse tanto para los textos poéticos como para los prosaicos. En los textos poéticos, antes de la porción de texto afectada por la variante, se especifica el número del verso como indicación topográfica; al contrario, en los textos en prosa la referencia topográfica deriva del número de folio (recto/verso) o página (cara), o incluso del número de párrafo (una segmentación del texto introducida modernamente, según los criterios que se expliciten en la "Nota al texto", e indicada en el margen externo, derecho o izquierdo, de la página de la edición crítica).

Veamos en concreto los vv. 64-68 de la Vita solitaria, representados con un aparato de tipo horizontal:

64 Odo sonar ne le romite stanze

65 L'arguto canto; a palpitar si move

66 Questo mio cor di sasso: ahi ma ritorna

67 Tosto al ferreo sopor, ch'è fatto estrano

68 Ogni moto soave al petto mio.

66-68 ritorna ... mio.] AN ${ }^{1}$ pensando | Che di lui (cf. v. l.) non si cura anima viva, | Riede al ferreo sopor, chè la più bella | Parte di questa vita il ciel negommi. de donde $\mathrm{T}$ (con pluma $C$ )

Veremos luego de forma más analítica el significado de las abreviaciones, de los diferentes cuerpos tipográficos, de la numeración de las fases del texto.

\subsection{Las variantes}

\subsection{Variantes inmediatas y variantes tardias}

Volvamos al manuscrito del Infinito. Si observamos con más atención el texto, podemos notar que las correcciones no son todas del mismo tipo, ya que se introdujeron con plumas diferentes y probablemente en momentos distintos.

Algunas, en particular la del v. 9, donde Leopardi enmienda "fra" por "tra", parecen haberse efectuado con una pluma diferente tanto de la em- 
pleada para escribir el texto base como de la utilizada para realizar las otras correcciones, una pluma de tinta más rojiza y con un trazo más fino. Otra observación que podemos hacer concierne al v. 7, donde el texto afectado por la variante queda idéntico en ambas redacciones finales. En efecto, nos hallamos ante una corrección efectuada en el momento de la primera redacción del texto, una enmienda que probablemente se debe a la anticipación del pronombre "mi" en la escritura del verso ("Io mi” corr. como "nel pensier mi fingo").

Una última observación atañe a la intervención manuscrita del v. 13, donde, con la misma pluma de la redacción base, Leopardi corrige la escritura errónea del apóstrofo ("e' l" corr. como "e 'l").

Todas estas observaciones nos llevan a considerar las variantes no como una unidad indiferenciada, sino como series distintas cronológicamente, como estratos de correcciones. El término "estrato" y la consecuente imagen de la estratificación geológica son particularmente indicados para representar la situación de un manuscrito, que presenta siempre al menos dos tipos de variantes: inmediatas y tardías.

Las variantes inmediatas son aquellas correcciones realizadas en el mismo momento de la redacción: se reconocen porque prevalentemente se hallan en el mismo renglón, es decir, porque el autor ha tachado el texto que acababa de escribir, sustituyéndolo en el mismo renglón con un texto diferente, para luego seguir escribiendo en la misma línea.

En el caso del texto del Infinito, la corrección del v. 7, "Io mi" $\rightarrow$ "nel pensier mi fingo", sin duda fue ejecutada en el mismo momento de la escritura del verso, porque, de no ser así, sería injustificado el espacio entre "Io" y "mi".

Naturalmente, una tachadura en el renglón no es forzoso indicio de una variante inmediata, porque si la tachadura afecta a una porción de texto accesoria y no necesaria para la intelección, podría haberse realizado en un momento sucesivo; como prueba el hecho de que el texto "funciona" igual al leerlo con la porción tachada o sin ella. Viceversa, en el caso de una corrección inmediata el texto leído con o sin la tachadura no tiene un sentido pleno ("Io mi nel pensier mi fingo": aun prescindiendo del sentido, el verso sería hipermétrico, elemento muy importante que es preciso tener en la debida cuenta cuando se trabaja sobre textos poéticos). 
Además, hace falta prestar siempre mucha atención a la caja de escritura de la página para distinguir las correcciones inmediatas de las tardías, porque el texto que figura en el margen externo, en sustitución de una porción de texto tachada en el renglón, es muy probable que se haya ańadido en un momento sucesivo a la redacción base, como se ve en la lámina 3.

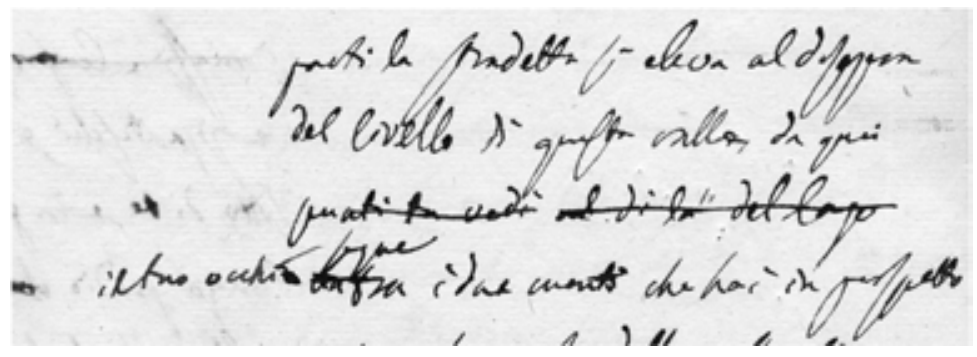

3. Alessandro Manzoni, Fermo e Lucia (t. I, cap. I, f. 4b)

Una categoría peculiar de variantes inmediatas es la de las variantes implicadas, es decir, de aquellas correcciones escritas por encima del renglón (suprascritas), por debajo (infrascritas) o anotadas en el margen derecho o izquierdo (adscritas), pero que tienen alguna implicación con el sentido de lo que sigue. La implicación, vale decir, el enlace entre los elementos textuales, puede ser sintáctica (concordancia de género o número), morfológica (concordancia de tiempos verbales), onomástica, toponomástica, etc.

Pongamos un ejemplo concreto, sacado del manuscrito del Fermo e Lucia (lámina 4). La corrección "una” $\rightarrow$ "un”, aun estando escrita en el espacio interlineal encima del renglón (suprascrita), es seguramente inmediata, es decir, contemporánea a la redacción base, porque está relacionada gramaticalmente con el sucesivo "galantuomo"; al contrario, la siguiente corrección "che", igualmente inserta en la interlínea, no puede considerarse inmediata, puesto que el texto tiene sentido pleno incluso sin la inserción: "che sa cosa vuol dire parlare" $\rightarrow$ "che sa che (ins.) cosa vuol dire parlare".

En cambio, las variantes tardías son aquellas correcciones realizadas en el texto en una fase sucesiva a la de la primera versión; son -en rigor- todas aquellas no colocadas en el renglón y que no tienen una implicación 
con el texto siguiente. Como es obvio, pueden reconocerse con certeza solo cuando el escritor ha utilizado dos plumas diferentes para las dos fases de elaboración del texto: una pluma para la redacción base, otra para la corrección; o bien en el caso que se consiga encontrar una serie de correcciones sistemáticas y comunes dentro del texto, como un cambio onomástico o toponomástico, o incluso teniendo en cuenta los hábitos gráficos o léxicos de escritura del autor (lo cual pone de manifiesto la gran importancia de un conocimiento profundizado de la lengua y del estilo del texto que se pretende editar y la interdependencia constante entre filología, historia de la literatura e historia de la lengua).

Además, el autor puede volver sobre el texto aun poco después de haber escrito la primera línea, aportando una corrección interlineal (por encima o por debajo del renglón) o marginal, que desde el punto de vista topográfico se considera tardía, aun cuando desde el punto de vista cronológico sea contemporánea del texto base. ¿Cómo se puede discernir en estos casos, dentro de la vasta categoría de las variantes interlineales (suprascritas e infrascritas) no implicadas, las que son realmente tardías, es decir, las que se corresponden con un sucesivo momento de revisión del texto, con un estrato de corrección?

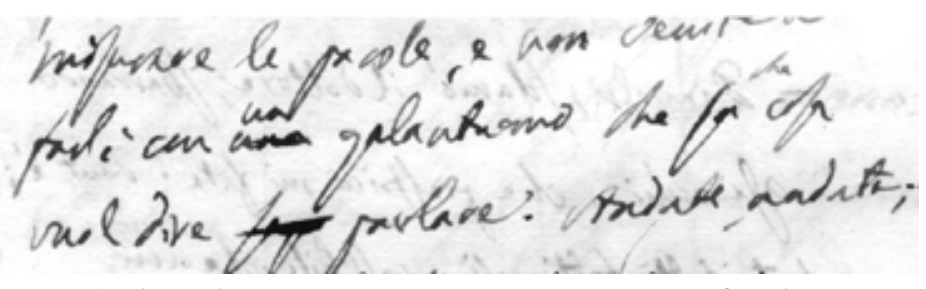

4. Alessandro Manzoni, Fermo e Lucia (t. I, cap. III, f. 29d)

A falta de específicos indicadores gráficos (plumas o bolígrafos, lápices de colores, etc.), será preciso tener en cuenta varios factores, como el ductus (el movimiento de la pluma sobre el folio), la grafía, las conexiones sintácticas y léxicas, el estilo del autor, sus hábitos de corrección, ninguno de los cuales nos brinda la certeza científica de la contemporaneidad o posteridad de la enmienda, pero que pueden concurrir todos, formando un «sistema», para sostener una u otra hipótesis cronológica.

Como en el caso, muy complejo, de las variantes tardías introducidas en el manuscrito del Fermo e Lucia, de las cuales algunas pertenecen a una 
revisión final del texto del Primer Borrador y otras a una revisión inicial del texto del Segundo Borrador, titulado los Sposi promessi, que, como es sabido, por varios capítulos del I tomo y algunos folios del IV, se escribió en los mismos folios, profundamente corregidos, del Fermo e Lucia ${ }^{38}$.

De estas consideraciones se infiere que la filología de autor (y toda la filología en general), aun no siendo una ciencia exacta, interpreta los datos que posee aplicando un método científico, formulando la hipótesis más razonable para la exégesis de esos datos, y admitiendo que siempre puede emerger algún nuevo elemento que no sea explicable con la hipótesis propuesta y que, en consecuencia, la invalide.

\subsubsection{Aparato horizontal hablado o simbólico}

Al contrario del aparato vertical, que no necesita abreviaciones y símbolos porque confía la representación de la diacronía correccional a la verticalidad de las variantes en columna, el aparato horizontal requiere indicaciones y símbolos para ahorrarse la explicación verbal y analítica de cada variante. Un aparato funcional debe ser racional y sintético, y por ello representará de manera uniforme los mismos fenómenos gráficos con oportunos indicadores. Dichos indicadores pueden utilizar abreviaciones o símbolos, lo cual genera la distinción entre:

1) aparato hablado: cuando se emplean abreviaciones para significar fenómenos de corrección homogéneos;

2) aparato simbólico: cuando con la misma finalidad se utilizan símbolos.

Por ejemplo, para representar uno de los casos más frecuentes en los textos manuscritos, o sea, la sustitución de una variante por otra, se puede utilizar la abreviación genérica corr. como (corregido como) o bien una flecha direccional $\rightarrow$ que incluso puede diferenciarse por categorías de variantes (flecha simple $\rightarrow$ para las variantes inmediatas, flecha bicolor $>$ para las variantes tardías).

$\mathrm{Si}$, además, una variante se inserta en la interlínea, el aparato hablado emplea la abreviación ins., que indica que el texto en el manuscrito se

38 Cf. Paola Italia y Giulia Raboni, “3.4. Manzoni: il Fermo e Lucia e la Seconda minuta”, en Che cosè la filologia d'autore, pp. 90-99. 
ha insertado en la interlínea superior (para una lección introducida en la interlínea inferior, caso menos frecuente, se ofrecerá una ulterior aclaración, como ins. en interl. inf. = insertado en la interlínea inferior). Para esta misma clase de correcciones, el aparato simbólico puede utilizar, en cambio, signos particulares (como la barra oblicua para aislar la palabra insertada: (palabra/).

Pero muy comunes son los aparatos de tipo mixto, hablado-simbólico, que adoptan abreviaciones y símbolos para representar de forma sintética y uniforme los fenómenos de corrección.

Las abreviaciones figuran siempre en cursiva, para que se pueda distinguir el texto del editor y el del autor, y se explicitan, igual que los símbolos, en una tabla que suele colocarse después de la "Nota al texto".

\subsubsection{Aparato fotográfico y aparato diacrónico}

Estas primeras indicaciones muestran una diferencia fundamental entre los aparatos: unos representan la dinámica de las correcciones, otros brindan una transcripción tipográfica del estado del manuscrito. En esta dicotomía estriba la profunda diferencia entre la filología de autor practicada en Italia y la génétique francesa (pero se puede incluir en el discurso también la Editionswissenschaft alemana), que es más propensa a representar las variantes tal como se presentan en el manuscrito, sin una distinción -como hemos visto- entre texto y aparato, respetando la misma topografía del texto (las variantes suprascritas se reproducen en la interlínea superior, las porciones de texto añadidas marginalmente figuran así también en el texto impreso, etc.).

En la estela del método de representación de las variantes leopardianas que empleó Moroncini, se han desarrollado técnicas de formalización cada vez más refinadas, sobre todo gracias a Isella y a su escuela, que pretenden representar las dinámicas diacrónicas del texto, y en los últimos diez ańos se ha asistido, en la filología de autor aplicada en Italia, a la transición definitiva hacia un aparato de tipo diacrónico y sistémico, que coloca la escuela filológica italiana en la vanguardia, aun dentro de un contexto europeo. Veamos algún ejemplo. 
Al principio, también en los primeros aparatos de filología de autor de tipo horizontal, la intención del filólogo era la de representar tipográficamente la compleja fenomenología del texto, es decir, ofrecer una transcripción tipográfica a través de abreviaturas y símbolos, prestando particular atención a las indicaciones que dependían de una oportuna simbología o de un sistema de exponentes. En la edición del códice chigiano de las Rime de Tasso, por ejemplo, dirigida por Gavazzeni ${ }^{39}$, dichas indicaciones se dan con una letra volada ańadida a la variante para aclarar su posición en la interlínea superior (a), en la interlínea inferior (b), en el margen derecho $(\mathrm{c})$, en el margen izquierdo $(\mathrm{d})$. Un auxilio útil para una mejor interpretación de un manuscrito de difícil desciframiento ${ }^{40}$.

Lo mismo se puede decir de los aparatos más representativos de la filología de autor del XX, los de las obras de Carlo Emilio Gadda, a partir de la edición crítica de 1983 del Racconto italiano di ignoto del Novecento; precisamente desde esta edición -en virtud de la ya rememorada distinción del triple filtro para racionalizar todo el material textual que no coincide con la lección fijada como texto: es decir, aparato, apostillas y variantes alternativas ${ }^{41}$ - se suele hacer arrancar una nueva fase, más científica y metodológicamente innovadora, de la filología de autor.

En cambio, en los aparatos realizados a partir de finales de los noventa se ha pretendido representar cada vez más las fases de la evolución del texto, y no ya la simple colocación topográfica de cada variante; fases que se conectan recíprocamente a través de una relación diacrónica. No se trata, por tanto, de mostrar cómo una variante se realiza gráficamente en relación con el texto anterior (inserta en la interlínea superior o inferior, en los márgenes, etc.), sino cómo la variante se relaciona desde un punto de vista diacrónico con la lección precedente. La diferencia principal -y la principal dificultad en la realización del aparato- consiste en la posibilidad de confrontar las fases con el texto final, en su individuación dentro de un "sistema": "en el aparato [...] la porción de texto sujeta a variación

39 Torquato Tasso, Rime d'amore, eds. Franco Gavazzeni, Marco Leva y Vercingetorige Martignone, Modena, Panini, 1993.

40 Cf. Paola Italia y Giulia Raboni, “3.3. Tasso: le Rime d'amore”, en Che cos’è la filologia d'autore, pp. 84-90.

41 Cf. Paola Italia y Giulia Raboni, "3.6. L'opera di Carlo Emilio Gadda”, en ibidem, pp. 109-115. 
(la que precede al corchete) siempre se puede cotejar con la variante o las variantes, de manera que se puedan estudiar de forma directa y autónoma sin acudir al «texto»" 42 .

La principal ventaja de este aparato es su autonomía, la posibilidad para el estudioso de seguir la génesis del texto desvinculada de su representación fotográfica (favorecida esta, no obstante, por la disponibilidad de reproducciones digitales de alta definición, que permiten distinguir, mediante el ductus y la grafía, las varias campañas de corrección del texto).

No aparatos que sirvan para una mejor interpretación del autógrafo, sino aparatos que sean ellos mismos una interpretación del autógrafo, hasta el punto de trasformar su lectura en una verificación, en paralelo, del trabajo de exégesis filológica y análisis crítico. Es cierto que para realizar este tipo de aparatos es necesario dedicar mucho más tiempo que en el pasado al examen del manuscrito, para intentar comprender más hondamente el "mecanismo" de la corrección, de la construcción lingüística, en poesía o en prosa. Porque una cosa es representar topográficamente las variantes, y otra muy diferente es disponerlas en un sistema diacrónico.

\subsubsection{Aparato horizontal progresivo o derivativo}

Otra distinción en los aparatos horizontales se hace entre aparato progresivo o derivativo.

Una vez transcrita en el aparato la porción de texto a la que atañe la variante, pueden representarse, después del corchete cerrado, todas las correcciones de forma progresiva o derivativa, conforme al orden seguido en la cadena de las variantes.

En el aparato evolutivo las correcciones siguen un orden cronológico, progresivo, desde la primera hasta la última, señalando las transiciones con una flecha o con la abreviación corr. en:

lección del texto] A corr. en $\mathrm{B}$ corr. en $\mathrm{C}$ corr. en $\mathrm{D}$.

42 Franco Gavazzeni, "Introduzione", en Giacomo Leopardi, Canti e poesie disperse, Florencia, Academia de la Crusca, 2009, p. XLII. 
En el aparato genético las correcciones siguen, en cambio, el orden contrario, derivativo, desde la última hasta la primera: la cadena de las variantes empieza con la abreviación de seguida por la penúltima corrección, lo cual significa que la lección del texto es obtenida de la penúltima y que esta a su vez es obtenida de la antepenúltima, etc., hasta llegar a la primera lección:

\section{lección del texto] de $\mathrm{D}$ de $\mathrm{C}$ de $\mathrm{B}$ de $\mathrm{A}$}

No obstante, de vez en cuando las correcciones pueden representarse en los aparatos de manera tanto progresiva como derivativa.

Las fases de corrección, por ejemplo, se representan siempre de forma progresiva: ${ }^{1}$ de donde ${ }^{2}$ de donde ${ }^{3} \mathrm{etc}$; en cambio, las microcorrecciones dentro de una misma fase se representan de modo derivativo: ${ }^{1}$ de donde ${ }^{2}$ (esc. sob. $\left.a^{1}\right)$ de donde ${ }^{3}$ (marg. $\left.a^{1} e^{2}\right)$.

\subsection{Las apostillas y las variantes alternativas}

La gran novedad metodológica que ha caracterizado los nuevos aparatos realizados en la última década deriva, como ya se ha dicho, de la racionalización de los niveles textuales del manuscrito introducida por Isella en su edición de 1983 del Racconto italiano di ignoto del Novecento de Gadda: aparato, apostillas, variantes alternativas.

Veamos analíticamente todos estos elementos y cómo cada uno de ellos se relaciona con el texto, ya que este, a diferencia de lo que sucede en la filología de ascendencia francesa, es el eje de toda la edición crítica.

\subsection{El aparato}

Con "aparato" se designa una parte de texto en relación de subordinación gráfica (al pie de la página) y tipográfica (en un cuerpo menor) respecto al texto: subordinación que puede llegar a ser incluso absoluta sumisión cuando el aparato se relega al final del volumen, o ascender a una mayor dignidad cuando se destina a él un volumen entero y un cuerpo tipográfi- 
co idéntico al del texto (como en el caso de la edición de Isella del Fermo e Lucia).

\subsubsection{Las apostillas}

La definición más completa de apostillas es la que brinda el mismo Ise$1 \mathrm{a}^{43}$ en la mencionada edición crítica del Racconto italiano di ignoto del Novecento:

Las observaciones, escritas dondequiera, con las cuales Gadda suele glosar lo ya hecho o lo que deberá hacer: expresiones de desacuerdo o de satisfacción, advertencias o consejos a sí mismo; y también dudas (de vez en cuando manifestadas con un punto interrogante), y conexiones entre lugares diversos; además de indicaciones, presumiblemente más tardías, para facilitar la copia en limpio de determinados pasajes o de una destinación de estos ya fuera del horizonte del Cahier.

Tratándose de apostillas al texto, su colocación ideal sería en los márgenes, pero por exigencias tipográficas se recogen en un catálogo final ${ }^{44}$ :

Se avisa puntualmente al lector interesado dónde se sitúa cada una de ellas con un signo convencional colocado, en su lugar, justo en el margen de la página (>): algo parecido a la extrema reducción gráfica de una mano con el índice tendido utilizada en tiempos pasados.

La posición respecto al texto, como es fácil apreciar, es una mera indicación subsidiaria, tanto del punto de vista tipográfico como gráfico, ya que las apostillas no tienen valor de texto, sino de metatexto.

43 Carlo Emilio Gadda, Racconto italiano di ignoto del Novecento, ed. Dante Isella, Turín, Einaudi, 1993, pp. XXIV-XXV.

44 Ibidem. 


\subsubsection{Las variantes alternativas}

Siempre según la definición de Isella, las variantes alternativas, que no deben confundirse con las variantes genéticas y las evolutivas, son "lecciones competidoras entre las cuales el autor no logra decidirse, o, en cualquier caso, no deja entender con claros signos que sabe decidirse" ${ }^{45}$.

Las variantes alternativas se registran al pie de la página y se consignan con una letra volada (ya que los números volados se suelen usar para las notas del autor presentes en el texto).

$\mathrm{Su}$ relación con el texto es, en cambio, de paridad tanto tipográfica como gráfica (tienen el mismo cuerpo tipográfico del texto), porque en aquel punto no sabemos si el autor, en una sucesiva revisión del manuscrito, hubiera elegido la variante alternativa o la lección base, y por lo tanto el estatus de las variantes alternativas debe ser igual al del mismo texto.

Como se puede ver, apostillas y variantes alternativas se reconocen más en su condición de texto que de aparato: aquellas, en efecto, aparecen antes del verdadero aparato crítico y separadas de él, mientras que estas se hallan al pie de la página, en el mismo cuerpo tipográfico del texto, para remarcar su estatus de texto y no de aparato.

Esta distinción es muy importante y tiene repercusiones notables en las ediciones de textos con un único testimonio que, aun no definiéndose como "críticas", se presentan, no obstante, como "científicas", asimilables en todo y para todo a una edición crítica en cuanto a lo que se lee como texto, pero desprovistas de aparato. Estas ediciones -que desempeñan funciones de precisión y exhaustividad filológica, combinándolas con exigencias concretamente editoriales- cada vez más a menudo intentan salvar esta "taxonomía" que acabamos de examinar, informando al lector de las variantes alternativas (al pie de la página) y de las apostillas (en un apéndice separado, o en la "Nota al texto"), aunque no puedan (o aunque no tengan espacio para) ofrecer también el aparato genético y / o evolutivo (es el caso de las obras de Pasolini, publicadas en la colección "Meridiani" de Mondadori, preparada por Silvia de Laude y Walter Siti).

Esta sencilla distinción de niveles textuales constituye, sin embargo, la premisa de muchas ediciones críticas realizadas por el mismo Isella o su

45 Ibidem, p. XXXV. 
escuela, que han contribuido a brindar soluciones ecdóticas específicas, ediciones que muestran una cada vez más significativa evolución hacia un aparato diacrónico y sistémico.

\subsection{Los signos diacriticos y las abreviaciones}

En las ediciones críticas de filología de autor se utilizan los más variados signos diacríticos, y tampoco existe un uso común generalizado relativo a las abreviaciones. Aunque los estudiosos hayan manifestado la exigencia de una estandarización, todavía no se han llegado a establecer unos criterios homogéneos; en consecuencia, en cada nueva edición crítica el lector tiene que familiarizarse con el sistema que ha adoptado el editor. Para algunos fenómenos hay símbolos tipificados; al contrario, para otros existe una gran confusión, ya que los mismos símbolos se emplean para representar fenómenos distintos o incluso contrarios.

Veamos los principales signos diacríticos y símbolos para ofrecer útiles recomendaciones a quien se aprestara a preparar una edición crítica.

Una communis opinio se registra para el signo más utilizado, es decir, los corchetes []. Es sabido que los corchetes se emplean para evidenciar todo lo que pertenece al editor, como las integraciones de palabras truncadas, las explicaciones de ciertos fenómenos, las integraciones de lagunas textuales o de puntuación en los textos que no poseen una tradición impresa (aunque para la puntuación sea preferible indicar las integraciones en la "Nota al texto"). Allá donde nos topemos con unos corchetes, entenderemos enseguida que el texto ha experimentado una revisión editorial. Sin embargo, a veces se utilizan los paréntesis oblicuos $<>$ para representar este mismo fenómeno.

Igualmente estandarizado es el uso de tres puntos encerrados entre corchetes [...] o paréntesis (...) para indicar la pérdida de una porción de texto (se emplean con regularidad en las citas abreviadas).

En cambio, un corchete de cierre ] indica, como ya se ha visto, la separación, dentro del aparato, entre el texto y su variante. Todo lo que precede al corchete se halla en el texto, todo lo que sigue es la variante, que puede ser manuscrita o impresa, acompañada de las abreviaciones y los símbolos utilizados para dar explicaciones sobre su topografía y cronología. Los 
paréntesis oblicuos en posición invertida, por el contrario, suelen indicar una tachadura $>\mathrm{xxxxx}<$ que - sin embargo- puede representarse incluso con la cursiva. Pero hay que tener cuidado, porque en algunos aparatos la cursiva seńala lo que no varía ("invariante") y la tachadura se representa, en cambio, con los paréntesis oblicuos $<>$ (solución no muy feliz, puesto que, como hemos visto, estos se emplean para señalar una integración del texto o palabras de dudosa lectura, y es peligroso confiar a un mismo símbolo la representación de dos fenómenos diferentes).

En el aparato hablado se emplean abreviaciones para representar algunos fenómenos del manuscrito, indicadas en cursiva para distinguirlas del texto que figura en letra redonda. Este es un elenco de las principales abreviaciones utilizadas:

$\begin{array}{ll}\begin{array}{ll}\text { de }[\text { it. } d a] & \text { la lección deriva de otra anterior, reciclando } \\ \text { una o más letras; } & \\ \text { de donde } \mathrm{T}[\text { da cui } \mathrm{T}] & \begin{array}{l}\text { la lección final }(\mathrm{T}) \text { deriva de otra anterior, reci- } \\ \text { clando letras y/o palabras; }\end{array} \\ \text { corr. en }[\text { corr. in }] & \begin{array}{l}\text { la lección precedente se corrige en la lección } \\ \text { que sigue; } \\ \text { la lección final se escribe en la interlínea superior } \\ \text { respecto a otra lección tachada en el renglón; }\end{array} \\ \text { esc. sob. }[\text { sps. }] & \begin{array}{l}\text { la lección final se escribe en la interlínea inferior } \\ \text { respecto a otra lección tachada en el renglón; } \\ \text { la lección es insertada; }\end{array} \\ \text { esc. deb. }[\text { sts. }] & \begin{array}{l}\text { la lección final es precedida por otra lección ta- } \\ \text { chada en el renglón; }\end{array} \\ \text { ins. } & \text { la lección final es seguida por otra lección ta- } \\ \text { antes }[\text { prima }] & \text { chada en el renglón y luego abandonada. }\end{array} \\ \text { sigue }[\text { segue }] & \end{array}$

En el aparato no hablado estos símbolos se sustituyen con unos signos diacríticos equivalentes, con la diferencia que, mientras que en el aparato hablado es posible darse cuenta también de la topografía de la variante (si se sitúa en la interlínea superior, inferior o en los márgenes del texto), el no hablado tiene que omitir estas informaciones, o confiarlas (como ha hecho Isabella Becherucci en el aparato del Adelchi manzoniano ${ }^{46}$ ) a las notas al pie de la página ańadidas al mismo aparato.

46 Alessandro Manzoni, Adelchi, Florencia, Accademia della Crusca, 1998. 
El aparato no hablado utiliza las flechas para indicar la diacronía de las variantes:

1) flecha directa $\rightarrow$ para representar una corrección (sustituye a la abreviación corr. como);

2) flecha invertida $\leftarrow$ para representar una derivación (sustituye a la abreviación de).

En algunos casos, como hemos visto, para señalar la cronología de las variantes, pueden utilizarse dos tipos diferentes de flechas: sencilla (variante evolutiva inmediata) y bicolor (variante evolutiva no inmediata).

En el caso de fases de corrección particularmente dilatadas puede resultar provechoso representar las microenmiendas dentro de cada una de las fases.

Las indicaciones topográficas y diacrónicas, entre paréntesis que se evidencian en cursiva, se refieren a la palabra inmediatamente anterior a los paréntesis. Si las indicaciones se refieren a más palabras, se indica con un signo gráfico el punto a partir del cual comienza la parte de texto afectada por la variante. Este signo de separación puede representarse de diferentes maneras, con un circulito negro, con una estrella, con un asterisco, o con un semicorchete abierto $(\Gamma)$.

Cuando en una misma línea de aparato se hallan dos variantes distantes entre ellas, como signo de división se emplea un espacio fijo en blanco (cuatro o cinco pulsaciones), o un cuadrado $\square$, o incluso un guion ondulado - .

\subsection{Cómo se hace una edición crítica}

Veamos ahora en concreto cómo se hace la edición crítica de un manuscrito que alberga diferentes series de correcciones.

Tomemos, como ejemplo, un texto leopardiano muy conocido y particularmente indicado por la calidad y la cantidad de las enmiendas: $L a$ luna o La ricordanza, cuyo manuscrito - perteneciente, igual que el del Infinito que ya hemos visto, al llamado "Cuaderno Napolitano"- se conserva con otros autógrafos leopardianos en la Biblioteca Nacional Vittorio Emanuele III de Nápoles (C.L. XIII.22). 
Delante del manuscrito leopardiano que, como se ha dicho, es una copia «en limpio» donde figuran, sin embargo, intervenciones de vario género, la primera pregunta que nos asalta es: ¿qué lección debemos elegir para el texto?

Si decidimos documentar la última lección del manuscrito, tenemos que transcribir el texto incluyendo en él todas las correcciones, inmediatas y tardías; vale decir: aquellas escritas con la pluma base (utilizada para la redacción primigenia del texto) y aquellas escritas sucesivamente. Una vez terminada la edición del texto podemos comenzar a transcribir las correcciones y a colocarlas en el aparato. Al optar por publicar la última lección del manuscrito, nuestro aparato será genético y representará, indicándolas con exponentes numéricos, las fases de la corrección, utilizando un cuerpo menor (de dos puntos) para las tachaduras en el renglón, y registrando las ulteriores correcciones entre los paréntesis en cursiva (los cuales, para no estorbar la lectura de las etapas correccionales, también figurarán en un cuerpo menor).

Podemos ver concretamente una ejemplificación de este método en la representación de las correcciones al título, que pasa de "“La Luna" a ${ }^{2 " L a}$ Luna o la Ricordanza" a "La Ricordanza". No olvidemos que las fases se indican siempre con un número volado, que entre una fase y otra se deben dejar por lo menos dos pulsaciones de separación y que, si una fase deriva de otra por reciclaje de material textual -como una o más letras-, esta deberá introducirse con la abreviación de donde, o con una flecha directa $\rightarrow$.

¿Por qué razón consideramos que el título originario fuese "La Luna" y no "La Luna o la Ricordanza"? En este caso no es posible seguir solo las indicaciones procedentes del ductus o de la tinta (que son idénticos en las dos fases), pero útiles elementos se obtienen de la posición topográfica en el texto. Si el título originario hubiera sido "La Luna o la Ricordanza", el autor lo habría colocado en el centro exacto de la página, y no desplazado a la derecha como se ve en el autógrafo. Esto significa que el título "La Luna" ya se había escrito y que Leopardi añadió marginalmente a la derecha la segunda parte del rótulo "o la Ricordanza", interviniendo luego, en una tercera fase, mediante la corrección de la "l" del artículo de minúscula a mayúscula. Esta enmienda, sin embargo, no parece coetánea de la escritura base, ya que guarda más bien cierta semejanza con algunas 
correcciones interlineales en los vv. 2, 7-8 y 9. Son enmiendas llevadas a cabo, en efecto, en una fase sucesiva y contemporánea a la escritura de los textos que siguen a La Luna en el "Cuaderno Napolitano" (el "segundo tiempo" de los Idillit $^{47}$ ).

Como sugiere esta observación, es posible identificar diferentes niveles de corrección del texto, relativos a plumas diversas e indicados con letras alfabéticas (A, B, C, D): estas acompañan a los números volados de las varias fases de corrección. En el caso de microenmiendas, como la del v. 5, la indicación de la pluma figura entre los paréntesis en cursiva, en cuerpo menor. En efecto, dentro de una etapa correctora pueden darse ulteriores variantes que, para no obstaculizar la lectura de la misma fase, se representan en cuerpo menor y de forma derivativa, como en el caso del v. 4:

(su quella selva] ${ }^{1 \mathrm{~A}}$ sopra quel bosco, de donde ${ }^{2 \mathrm{~A}}$ sopra quel prato, (con prato reescr. sobre bosco ${ }^{3 \mathrm{~A}}$ su quella selva, (marg. $\left.a^{2}\right)$ de donde ${ }^{\mathrm{B}} \mathrm{T}$ )

El ejemplo nos permite profundizar mejor en el uso de las abreviaciones de, de donde y de donde T. La primera se emplea para indicar una corrección en la cual el texto final vuelve a utilizar una o más letras de la lección precedente. Al contrario, la abreviación de donde (que también puede sustituirse con la flecha $\rightarrow$ ), identifica el reciclaje, en la variante sucesiva, de una ancha porción de texto de la variante anterior. Cuando este último caso desemboca en la lección del texto se usa la abreviación de donde $\mathrm{T}$ (también representable con la flecha $\rightarrow \mathrm{T}$ ).

La representación de las variantes en los vv. 7-8 muestra, en cambio, qué entendemos concretamente por aparato diacrónico y sistémico. La primera definición depende del hecho de que este aparato no asume la responsabilidad de representar la topografía de la corrección (es decir, no aclara dónde se sitúan las variantes, si encima, debajo, a la derecha o a la izquierda del texto), señalando solo su diacronía, su evolución desde un «antes» hasta un «después» que se identifican con fases numéricas (aquí las fases son cuatro, si se cuenta también la última que coincide con la lección del texto). La definición de sistémico, en cambio, se debe aplicar porque las correcciones se representan no

47 Paola Italia, "I tre tempi degli Idilii: le proiezioni”, Filologia italiana, III, 3 (2007), pp. 173-213. 
de forma individual, ligando cada una de ellas a la palabra (o palabras) a la que se refiere topográficamente, sino contextualizándolas dentro de un sistema de enmiendas, e incluyendo en la porción final todo el texto afectado por la variante: la variante, en efecto, puede exceder la estrecha medida del verso para interesar también el verso sucesivo (aquí los vv. 7-8).

Este ejemplo nos ayuda a comprender que, para los aparatos de tipo vertical que fragmentan las variantes y las conectan estrechamente a los elementos más cercanos topográficamente, es muy difícil, por no decir imposible, representar las correcciones que atañen a dos o más versos $^{48}$.

En la edición del manuscrito de Alla Luna, debajo de la sección del aparato genético, se halla un recuadro que recoge la llamada varia lectio, o sea, aquel conjunto de variantes, citas, notas de aclaración lingüística, observaciones metatextuales que Leopardi solía apuntar en sus propios manuscritos y que hallamos, aunque en menor medida respecto a otros autógrafos napolitanos, también en el manuscrito de Alla luna, donde, en el margen derecho, y transversalmente respecto a la caja de escritura, Leopardi anota una variante, probablemente en una fase tardía de corrección del manuscrito, según delata la tinta rojiza (aquí catalogada como pluma D).

Una ulterior sección de aparato, debajo del recuadro de la varia lectio, es ocupada por las Notas filológicas: estas van en letra cursiva para distinguirlas del aparato (al contrario, cuando se hallan en la "Nota al texto", normalmente figuran en letra redonda). Dichas notas desempeñan la tarea de explicar de forma muy analítica la fenomenología de los manuscritos y la dinámica de las correcciones, proponiendo varias interpretaciones del texto o señalando los casos de dudosa lectura. En las "Notas filológicas" se puede insertar, a manera de comentario, todo lo que se quisiera decir para justificar determinadas decisiones tomadas en el aparato y que no sería posible detallar en el breve espacio al pie del texto. Un criterio para entender si una elección ecdótica es oportuna o no consiste en valorar la relación entre el grado de análisis y la economía de la representación. Un buen aparato, en efecto, es el que representa de

48 Véase el examen detallado de estos versos en Paola Italia y Giulia Raboni, “3.5. Leopardi: los Cantì', en Che cos'e la filologia d'autore, pp. 99-109. 
la forma más precisa, clara y sintética el manuscrito y sus correcciones, transformando lo que al principio es un objeto visivo e icónico en un texto dinámico.

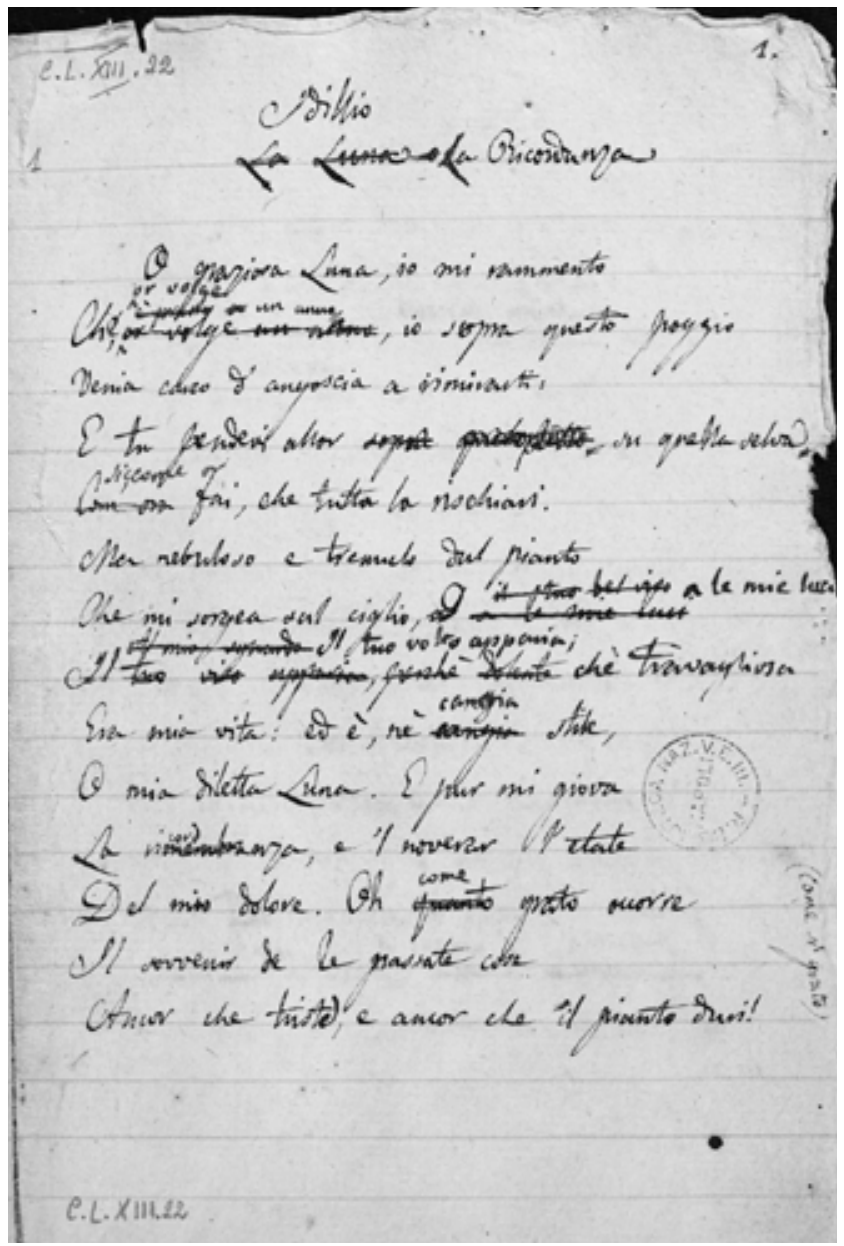

Giacomo Leopardi, Idillio | La ricordanza (C.L. XIII.22, p. 1)

AN p. 1 
Idillio

La Ricordanza

1 O graziosa Luna, io mi rammento

2 Che, or volge un anno, io sopra questo poggio

3 Venia carco d'angoscia a rimirarti:

$4 \quad$ E tu pendevi allor su quella selva

5 Siccome or fai, che tutta la rischiari.

6 Ma nebuloso e tremulo dal pianto

$7 \quad$ Che mi sorgea sul ciglio, a le mie luci

8 Il tuo volto apparia; chè travagliosa

9 Era mia vita: ed è, nè cangia stile,

10 O mia diletta Luna. E pur mi giova

11 La ricordanza, e 'l noverar l'etate

12 Del mio dolore. Oh come grato occorre

13 Il sovvenir de le passate cose

14 Ancor che triste, e ancor che il pianto duri!

tit. La Luna o La Ricordanza] ${ }^{1 \mathrm{~A}} \mathrm{La}$ Luna de donde ${ }^{2 \mathrm{~A}} \mathrm{La}$ Luna o la Ricordanza de donde ${ }^{3 \mathrm{~B}} \mathrm{La}$ Ricordanza (con L sobre 1)

2 Che, or volge un anno,] ${ }^{1 \mathrm{~A}} \mathrm{Ch}$ 'or volge un anno, (con an sobre al) de donde ${ }^{2 \mathrm{~A}}$ Ch'è presso a un anno, de donde ${ }^{3 \mathrm{~B}} \mathrm{~T}$ sopra] de su (pluma A)

4 su quella selva] ${ }^{1 \mathrm{~A}}$ sopra quel bosco, de donde ${ }^{2 \mathrm{~A}}$ sopra quel prato, (con prato reescr. sobre bosco) ${ }^{3 \mathrm{~A}}$ su quella selva, (marg. $a^{2}$ ) de donde ${ }^{\mathrm{B}} \mathrm{T}$

5 Siccome or] esc. sob. a Com'ora (pluma B)

7-8 a le mie luci | Il tuo volto apparia; chè travagliosa] ${ }^{1 \mathrm{~A}} \mathrm{a}$ le (antes alle») mie luci | Il tuo viso apparia, perchè dolente de donde ${ }^{2 \mathrm{~A}} \mathrm{il}$ tuo bel viso $\mathrm{Al}$ mio sguardo apparia, perchè dolente ${ }^{3 \mathrm{~B}}$ a le mie luci | Il tuo volto apparia, che travagliosa de donde ${ }^{4 \mathrm{D}} \mathrm{T}$

9 cangia] ${ }^{1 \mathrm{~A}}$ cangia ${ }^{2 \mathrm{~B}}$ cambia (esc. sob. $a^{1}$ ) de donde ${ }^{3 \mathrm{D}} \mathrm{T}$

11 ricordanza] de rimembranza (pluma $A$ )

12 come] esc. sob. a quanto (pluma $B$ )

14 triste] de tristi (pluma B) il] de 'l (pluma C?) 
AN fol. [1r]

marg. derecho transv.

(12) (come sì grato) (pluma D)

tit. El titulo inicial del texto, que al principio era solo "La Luna", se corrige, con la misma pluma con la cual se escribe el texto base (A), en "La Luna o la Ricordanza", y sucesivamente, con la pluma $B$, en "La Ricordanza". Las dos fases $A$ de escritura del título se han identificado en virtud de la costumbre de Leopardi de escribir el título en el centro exacto y debajo de "Idillio" (como en "La sera del giorno festivo" y en "La vita solitaria").

2 Con la pluma A se efectúa la primera corrección ("Ch’è presso a un anno,"), como sucede también en los 7-8 y 11.

4-5 Las correcciones con tinta más densa pertenecen a la fase $B$.

7-8 Como ya apuntó De Robertis (en Leopardi, 1984, vol. II, p. 327), la corrección de la coma en un punto y coma después de "apparia" y la acentuación de "che", parecen pertenecer a la pluma de color rojizo (aqui con sigla $D$ ).

9 La corrección de "cambia" en "cangia" se realiza tardiamente (De Robertis en Leopardi, 1984, vol. II, p. 327) con la pluma D, la misma que al v. 8 introduce el acento grave en "che" y con la cual Leopardi escribe la variante en el marg. transv. derecho "(come si grato)"; en la edición "come" no se reproduce con negrita porque se supone que la corrección del v. 12: "quanto" $\rightarrow$ "come", con pluma $B$ (distanciándose de Lucchesini en Leopardi, 2009, vol. I, p. 278, que juzga la corrección con pluma A), no se ha efectuado después, sino antes de la escritura de la varia lectio.

14 La corrección sobre "triste" cubre el punto de la "i" con el lazo de la " $e$ ", obligando a una rúbrica anómala en la escritura habitual de la vocal. La corrección de "l" como "il" podría pertenecer a la fase $C$; en cambio, por el carácter serial de la intervención la varia lectio marginal se aproxima más a la fase $D$, con la cual comparte ductus y color rojizo (siempre De Robertis en Leopardi, 1984, vol. II, p. 327). 